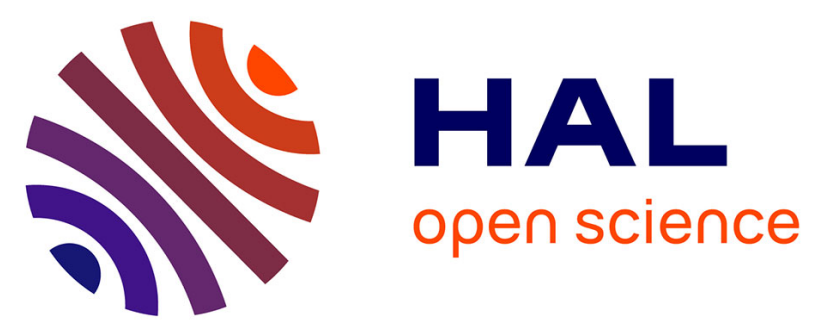

\title{
Octahedral Hexachloro Environment of Dy3+ with Slow Magnetic Relaxation and Luminescent Properties
}

Nesrine Benamara, Mayoro Diop, Cedric Leuvrey, Marc Lenertz, Pierre Gilliot, Mathieu Gallart, Hélène Bolvin, Fatima Setifi, Guillaume Rogez, Pierre Rabu, et al.

\section{To cite this version:}

Nesrine Benamara, Mayoro Diop, Cedric Leuvrey, Marc Lenertz, Pierre Gilliot, et al.. Octahedral Hexachloro Environment of Dy3+ with Slow Magnetic Relaxation and Luminescent Properties. European Journal of Inorganic Chemistry, 2021, 22, pp.2099-2107. 10.1002/ejic.202100143 . hal-03268319

\section{HAL Id: hal-03268319 https://hal.science/hal-03268319}

Submitted on 24 Jun 2021

HAL is a multi-disciplinary open access archive for the deposit and dissemination of scientific research documents, whether they are published or not. The documents may come from teaching and research institutions in France or abroad, or from public or private research centers.
L'archive ouverte pluridisciplinaire HAL, est destinée au dépôt et à la diffusion de documents scientifiques de niveau recherche, publiés ou non, émanant des établissements d'enseignement et de recherche français ou étrangers, des laboratoires publics ou privés. 


\title{
Octahedral Hexachloro Environment of $\mathrm{Dy}^{3+}$ with Slow Magnetic Relaxation and Luminescent Properties
}

Dr. Nesrine Benamara, ${ }^{[a, b]}$ Dr. Mayoro Diop, ${ }^{[a]}$ Cédric Leuvrey, ${ }^{[a]}$ Dr. Marc Lenertz, ${ }^{[a]}$ Dr. Pierre Gilliot, ${ }^{[\mathrm{a}]}$ Dr. Mathieu Gallart, ${ }^{[\mathrm{a}]}$ Dr. Hélène Bolvin, ${ }^{[\mathrm{c}]}$ Dr. Fatima Setifi, ${ }^{[\mathrm{b}]}$ Dr. Guillaume Rogez ${ }^{[a]}$ Dr. Pierre Rabu, ${ }^{[\mathrm{a}]}$ Dr. Emilie Delahaye ${ }^{* \mathrm{a}, \mathrm{d}]}$

a. Université de Strasbourg, CNRS, Institut de Physique et Chimie des Matériaux de Strasbourg, UMR 7504, 67034 Strasbourg, France.

b. Laboratoire de Chimie, Ingénierie Moléculaire et Nanostructures (LCIMN), Université Ferhat Abbas Sétif 1, Sétif 19000, Algeria.

c. Laboratoire de Chimie et de Physique Quantiques, Université de Toulouse and CNRS, 31062 Toulouse, France.

d. Present address: CNRS, Laboratoire de Chimie de Coordination, 205 route de Narbonne, 31077 Toulouse, France and Université de Toulouse, UPS, INPT, LCC, 31077 Toulouse, France.

\section{Keywords}

Ionic liquid, Imidazolium salt, Lanthanide, Single ion magnet, Luminescence

\section{Table of content}

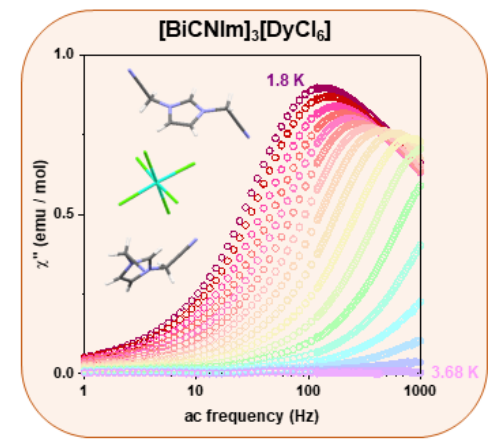

A new compound containing octahedral $\left[\mathrm{DyCl}_{6}\right]^{3-}$ entities has been synthesized solvothermally in presence of nitrilefunctionalized ionic liquid and its luminescent and magnetic properties have been studied. A Single Ion Magnet behaviour is observed which is compared to that of other rare-earth compounds exhibiting similar environment.

\begin{abstract}
The compound [ $\mathbf{B i C N I m}]_{3}\left[\mathbf{D y C l}_{\mathbf{6}}\right]_{\text {was }}$ synthesized from a nitrile-functionalized imidazolium ionic liquid $[\mathrm{BiCNIm}][\mathrm{Cl}]$ and $\mathrm{DyCl}_{3} \cdot 6 \mathrm{H}_{2} \mathrm{O}$ in acetonitrile using solvothermal conditions. Structural characterization reveals that the $\mathrm{Dy}^{3+}$ ions are in a quasi-regular octahedral environment, formed by six chloride anions. The magnetic study indicates that this mononuclear compound exhibits a Single Ion Magnet behaviour. This behaviour is compared
\end{abstract}


to that of other mononuclear compounds containing $\mathrm{Dy}^{3+}$ ions in various octahedral environment.

\section{Introduction}

Since the pioneering works on $\left[\mathrm{Mn}_{12} \mathrm{O}_{12}\left(\mathrm{CH}_{3} \mathrm{CO}_{2}\right)_{16}\left(\mathrm{H}_{2} \mathrm{O}\right)_{4}\right],{ }^{[1]}$ different synthetic strategies have been elaborated to obtain compounds with efficient Single Molecule Magnet (SMM) behaviours, i.e. usable as ultra-small magnetic bit for high-density data storage, integrated component for spintronics or Qbits for quantum applications. ${ }^{[2-11]}$ The use of SMM for such applications is strongly hampered by the low temperature necessary for stabilizing the SMM state $^{[7]}$ as well as low chemical stability, especially when integrated onto surfaces, ${ }^{[12-15]}$ or disentanglement/decoherence problem. ${ }^{[16-19]}$ Many efforts have initially concerned the elaboration of molecular compounds of high nuclearity to maximize the total spin moment of the system, combined with high anisotropy barrier. Despite many interesting achievements, ${ }^{[20-24]}$ the approach was much limited due to the difficulty for maintaining the local anisotropy of each magnetic centre in a particular direction and fully controlling the magnetic exchange pathways within the polynuclear entities. More recently, the possibility to build SMMs involving only one magnetic ion exhibiting high anisotropy, also called Single Ion Magnet (SIM), has been explored. In particular, the pioneering works on bis(phthalocyaninato)-lanthanide complexes have largely contributed to the success of this approach. ${ }^{[25,26]}$ Since then, different ligands were synthesized to tailor the coordination sphere around the lanthanide ion, giving the possibility to establish magneto-structural correlations, especially concerning the symmetries of the ligand

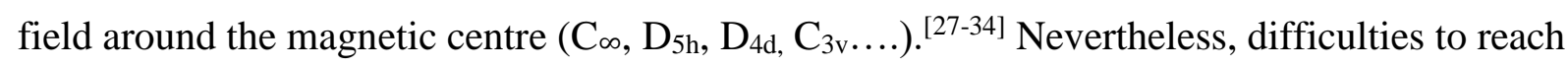
certain symmetries remain, principally related to the fact that lanthanide ions tends to present high coordination numbers. Regarding SIMs, only few examples of mononuclear compounds containing lanthanide ions in octahedral environment were reported. ${ }^{[35-45]}$

Possibility to achieve unusual coordination environments for $\mathrm{Ln}^{3+}$ ions was observed with the use of Ionic Liquids (ILs). ${ }^{[46]}$ In particular, the formation and stabilization of octahedral entities of formula $\left[\mathrm{LnCl}_{6}\right]^{3-}$ in the solid state was described using phosphonium or alkyl imidazolium ILs with Ln chloride salts. ${ }^{[47-49]}$ However, no information on possible slow relaxation of the magnetization was reported for these compounds.

This article describes the synthesis and the characterization of the compound [BiCNIm $]_{3}\left[\mathbf{D y C l}_{6}\right]$ obtained in solvothermal conditions by reacting $\mathrm{DyCl}_{3} \cdot 6 \mathrm{H}_{2} \mathrm{O}$ with the 1,3bis((cyanomethyl)imidazolium) chloride $\mathrm{IL}[\mathrm{BiCNIm}][\mathrm{Cl}]$. [ $\mathrm{BiCNIm}_{3}\left[\mathrm{DyCl}_{6}\right]$ is constituted 
of quasi-regular octahedral $\left[\mathrm{DyCl}_{6}\right]^{3-}$ entities surrounded by imidazolium cations $[\mathrm{BiCNIm}]^{+}$. The magnetic properties have been analyzed evidencing a SIM behaviour for the $\mathrm{Dy}^{3+}$ ions in this environment. The detailed analysis of the properties suggests a combination of Raman, Orbach and Quantum Tunneling (QTM) relaxation mechanisms. Luminescent properties at room temperature for this compound are also reported.

\section{Results and Discussion}

Synthesis

$[\mathbf{B i C N I m}]_{3}\left[\mathbf{D y C l}_{6}\right]$ has been synthesized in solvothermal conditions by reacting one equivalent of $\mathrm{DyCl}_{3} \cdot 6 \mathrm{H}_{2} \mathrm{O}$ with two equivalents of the nitrile-functionalized $\mathrm{IL}$ [BiCNIm] $[\mathrm{Cl}]$ in acetonitrile at $363 \mathrm{~K}$ for 2 days. After cooling down to room temperature, colorless crystals has been obtained.

It is worth to underline here that despite the final IL/Dy stoichiometry of 3/1, only the use of $50 \%$ excess of Dy (stoichiometry 2/1) provides the crystallization of [BiCNIm] 3 [DyCl6]. Several attempts to use other solvents (water or ethanol for instance) or to change the stoichiometry of the starting mixture did not lead to the title compound. In particular, starting with a 3/1 stoichiometry as observed in the title compound, or with a larger excess of Dy (200 $\%$ excess, stoichiometry $1 / 1$ ) resulted only in solutions, with no formation of any crystalline compound upon further crystallization attempts.

\section{Crystal structure of $[\mathrm{BiCNIm}]_{3}\left[\mathrm{DyCl}_{6}\right]$}

$[\mathrm{BiCNIm}]_{3}\left[\mathrm{DyCl}_{6}\right]$ crystallizes in the orthorhombic space group $P \mathrm{bcn}$. Selected crystallographic data for this compound are collected in Table S1.

The asymmetric unit consists in one $\mathrm{Dy}^{3+}$ ions positioned on 2-fold axis, three chloride anions coordinated to the $\mathrm{Dy}^{3+}$ ions and one and a half independent cations $[\mathrm{BiCNIm}]^{+}$(Figure S1). The repetition of this unit in the periodic structure, gives rise to $\left[\mathrm{DyCl}_{6}\right]^{3-}$ entities aligned along the $a$ axis and surrounded by $[\mathrm{BiCNIm}]^{+}$cations (Figure 1). 


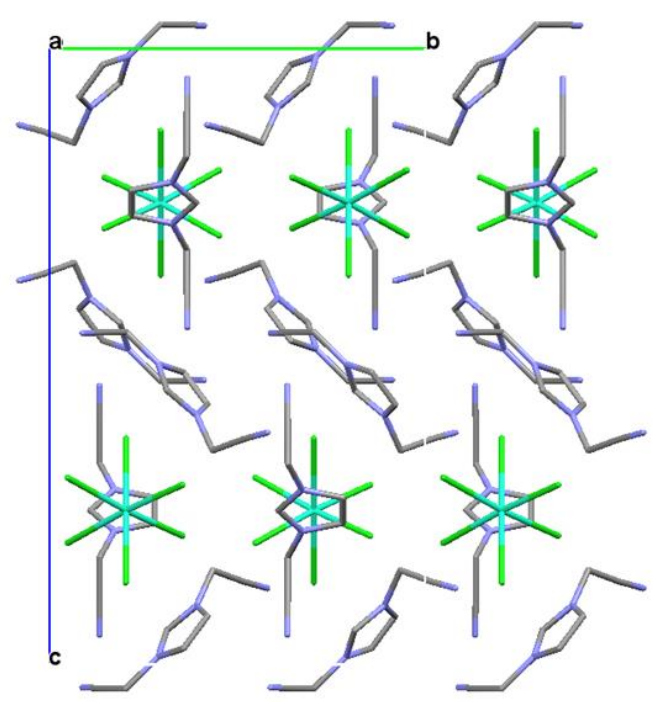

Figure 1. View showing the alternation of the cationic and anionic entities in [BiCNIm $]_{3}\left[\mathbf{D y C l}_{6}\right]$ along the $a$ axis (Dy in cyan, $\mathrm{Cl}$ in green, $\mathrm{C}$ in grey, $\mathrm{N}$ in blue, $\mathrm{H}$ are omitted for clarity).

The Continuous Shape Measures performed with the software SHAPE ${ }^{[50]}$ showed that the coordination sphere around the $\mathrm{Dy}^{3+}$ ion is a quasi-regular octahedron (Table S2). The Dy-Cl distances range between 2.630(1) $\AA$ and 2.645(1) $\AA$ (Figure 2 and Table S3). These values are similar to those reported in related hexachloro compounds. ${ }^{[48]}$ The four cis angles Cl1-Dy-Cl1 ${ }_{\mathrm{i}}$, $\mathrm{Cl} 1_{\mathrm{i}}-\mathrm{Dy}-\mathrm{Cl} 3, \mathrm{Cl} 3-\mathrm{Dy}-\mathrm{Cl} 3_{\mathrm{i}}$ and $\mathrm{Cl} 3_{\mathrm{i}}-\mathrm{Dy}-\mathrm{Cl} 1$ are comprised between $89.19(4)^{\circ}$ and $93.08(6)^{\circ}$ while the trans angle Cl2-Dy-Cl2 $2_{\mathrm{i}}$ is equal to $179.95(5)^{\circ}$ (Figure 2 and Table S3). The shortest distance between two adjacent $\mathrm{Dy}^{3+}$ ions is $8.9 \AA$.

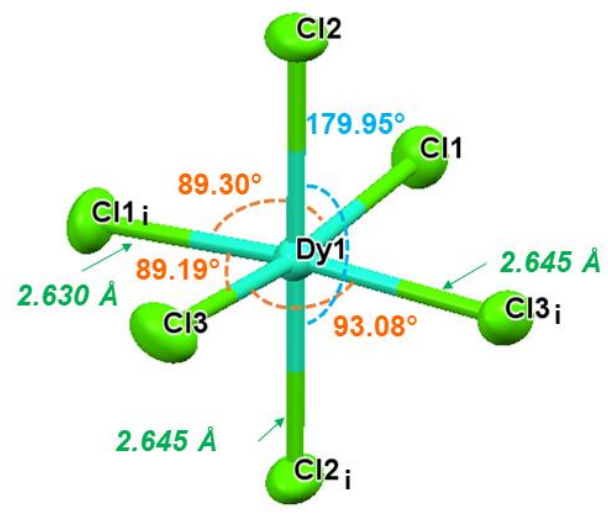

Figure 2. View in ellipsoid mode showing some selected Dy-Cl distances and Cl-Dy-Cl angles in the octahedral $\left[\mathrm{DyCl}_{6}\right]^{3-}$ entities contained in [BiCNIm $]_{3}\left[\mathbf{D y C l} \mathbf{C l}_{6}\right.$. Symmetry code: (i) 1-x, y, $1 / 2-\mathrm{z}$. 
Short interactions between chloride anions and hydrogens of the imidazolium moieties are responsible of the cohesion of the crystal (see Figure S2 and Table S4).

The phase purity of the compound obtained as crystalline powder has been investigated performing a Rietveld refinement on the powder X-ray diffraction (PXRD) pattern with the Fullprof software. ${ }^{[51]}$ It was observed that the crystal structure determined from the single crystal analysis is in agreement with the PXRD pattern (Figure S3). This study also revealed some additional peaks with low intensity (see purple arrows on Figure S3). These peaks have been attributed to the presence of a second phase likely stemming from the partial hydrolysis of the $\left[\mathrm{DyCl}_{6}\right]^{3-}$ entities as already observed in related compounds. ${ }^{[49]}$ However, as confirmed by elemental analysis and thermogravimetric analysis (Figure S4 and Figure S5), this second phase is a very minority phase and does not hamper the analysis of physical properties reported below since the decomposition product does not contribute to any of these properties. Actually, when it is left in air for few days, the compound turns to an amorphous powder (Figure S6) which is no longer luminescent and does not exhibit slow magnetic relaxation properties.

\section{Analysis of the luminescent properties}

The luminescent properties of the title compound $[\mathbf{B i C N I m}]_{3}\left[\mathbf{D y C l}_{\mathbf{6}}\right]_{\text {have }}$ been investigated in the solid state at room temperature (Figure 3, Figure S7 and Figure S8). Under excitation at $350 \mathrm{~nm}$, the emission spectrum displays a very broad band centered at $550 \mathrm{~nm}$ corresponding to the luminescence of the ligand (Figure S9) superimposed with two peaks centered at $574 \mathrm{~nm}$ and $668 \mathrm{~nm}$. These two peaks are assigned to the ${ }^{4} \mathrm{~F}_{9 / 2} \rightarrow{ }^{6} \mathrm{H}_{13 / 2}$ and ${ }^{4} \mathrm{~F}_{9 / 2} \rightarrow{ }^{6} \mathrm{H}_{11 / 2}$ transitions of $\mathrm{Dy}^{3+}$ ion, respectively. ${ }^{[52]}$ The intense band at $574 \mathrm{~nm}$ is responsible of the yellow emission color of the compound. The peak expected for the ${ }^{4} \mathrm{~F}_{9 / 2} \rightarrow{ }^{6} \mathrm{H}_{15 / 2}$ transition of $\mathrm{Dy}^{3+}$ ion, which is responsible for blue emission color (around $480 \mathrm{~nm}$ ), is not observed here. Actually, this feature is merely masked by the relatively intense signal of the ligand in comparison with the one coming from the lanthanide it-self.

In the excitation spectrum, monitoring the most intense transition at $574 \mathrm{~nm}$, we observe five bands at $350,363,385,451$ and $471 \mathrm{~nm}$ which can be ascribed to the transitions between the ground state ${ }^{6} \mathrm{H}_{15 / 2}$ and excited states ${ }^{4} \mathrm{M}_{15 / 2}+{ }^{6} \mathrm{P}_{7 / 2},{ }^{4} \mathrm{I}_{11 / 2},{ }^{4} \mathrm{M}_{21 / 2}+{ }^{4} \mathrm{I}_{13 / 2}+{ }^{4} \mathrm{~K}_{17 / 2}+{ }^{4} \mathrm{~F}_{7 / 2},{ }^{4} \mathrm{I}_{15 / 2}$, and ${ }^{4} \mathrm{~F}_{9 / 2}$ of $\mathrm{Dy}^{3+}$ ion, respectively. ${ }^{[41]}$ These bands are also in keeping with the absorption spectra (Figure S10). 


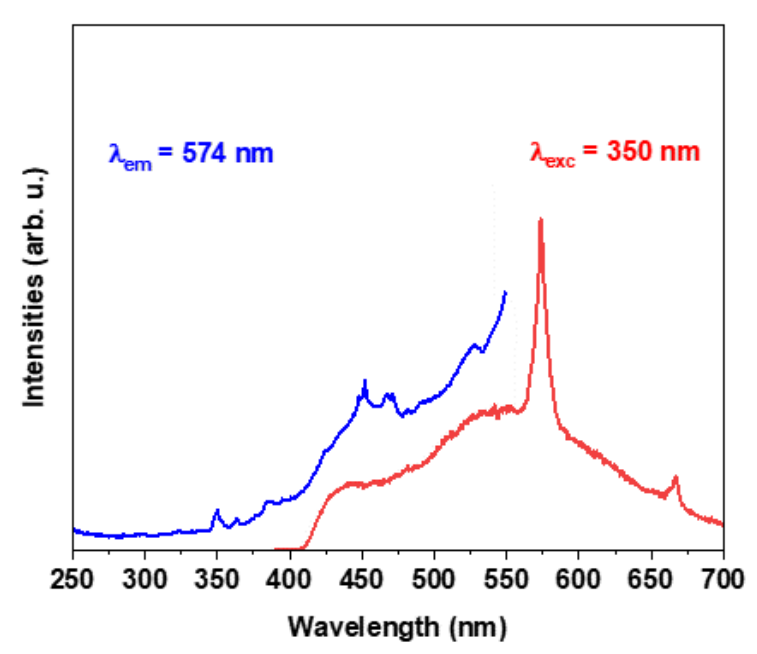

Figure 3. Photoluminescence spectrum (red line) and photoluminescence excitation spectrum (blue line) at room temperature and in solid state for [BiCNIm] $]_{3}\left[\mathbf{D y C l}_{6}\right]$.

\section{Magnetic study}

The static susceptibility measurement was performed in the $1.8-300 \mathrm{~K}$ temperature range with an applied field of 5000 Oe (Figure 4). The $\chi T$ value at room temperature $\left(13.2 \mathrm{emu} \cdot \mathrm{K} \cdot \mathrm{mol}^{-1}\right)$ is in good agreement with the expected value of $14.17 \mathrm{emu} \cdot \mathrm{K} \cdot \mathrm{mol}^{-1}$ for mononuclear Dy ${ }^{\mathrm{III}}$ ion $\left(S=5 / 2, L=5,{ }^{6} \mathrm{H}_{15 / 2}, g=4 / 3\right) .{ }^{[53]}$ Upon cooling, the $\chi T$ product decreases, because of a combination of thermal depopulation of excited $\mathrm{M}_{\mathrm{J}}$ sublevels and significant magnetic anisotropy. Magnetization is not saturated even at $7 \mathrm{~T}$ because of strong magnetic anisotropy (Figure S11).

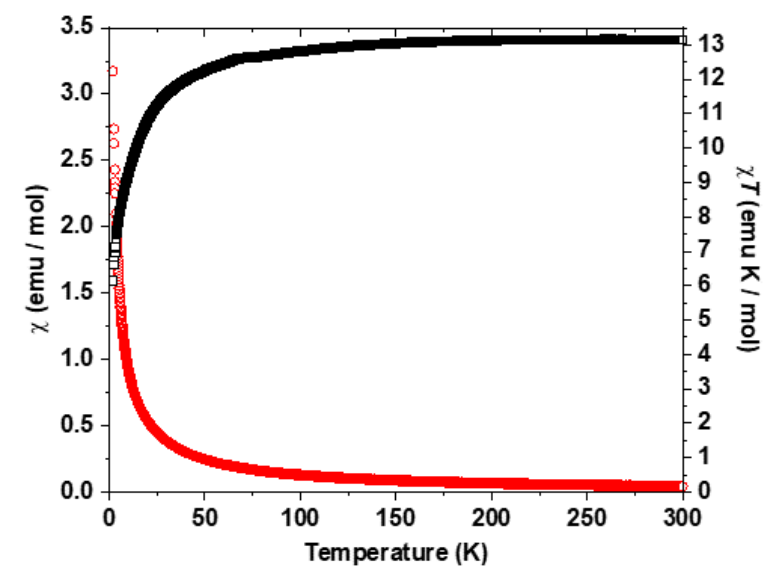

Figure 4. $\chi T$ vs. $T$ (black squares) and $\chi v s . T$ (red circles) for [BiCNIm] 3 [DyCl6] under a static dc field of 5000 Oe. 
Under zero $d c$ field and at $1.8^{\wedge \wedge} \mathrm{K}$, no out-of-phase signal is observed in the $a c$ frequency range investigated, merely due to Quantum Tunneling of Magnetization (QTM). ${ }^{[1]}$ Further measurements were carried out under a small $d c$ field. The optimum field value to reduce QTM was chosen as the one that provides the slowest magnetic relaxation (Figure S12a and Figure $\mathrm{S} 12 \mathrm{~b}$ ), i.e. 500 Oe. It can be seen on Figure S12a, there are (at least) two relaxations modes, one at high frequency in low fields (between 100 and $1000 \mathrm{Oe}$ ), and another one at low frequencies, which appears when the applied dc field increases.

Finally, $a c$ susceptibility measurements were performed as a function of the $a c$ field frequency between $1.8 \mathrm{~K}$ and $3.86 \mathrm{~K}$ under this optimized dc field of 500 Oe determined above (Figure S13 and Figure5).

Figure S14 shows the corresponding Cole-Cole plot. It appears clearly on this plot, but also on the $\chi^{\prime}=\mathrm{f}(v)$ and $\chi^{\prime \prime}=\mathrm{f}(v)$, that the distribution of the relaxation times for this compound is nonsymmetrical. Therefore, a generalized Debye model is unable to fit properly the $a c$ data (Figure S15). ${ }^{[54,55]}$ This asymmetry of the relaxation time distribution at 500 Oe can be due to the vicinity of different relaxation modes, difficult to discriminate or to some structural disorder.

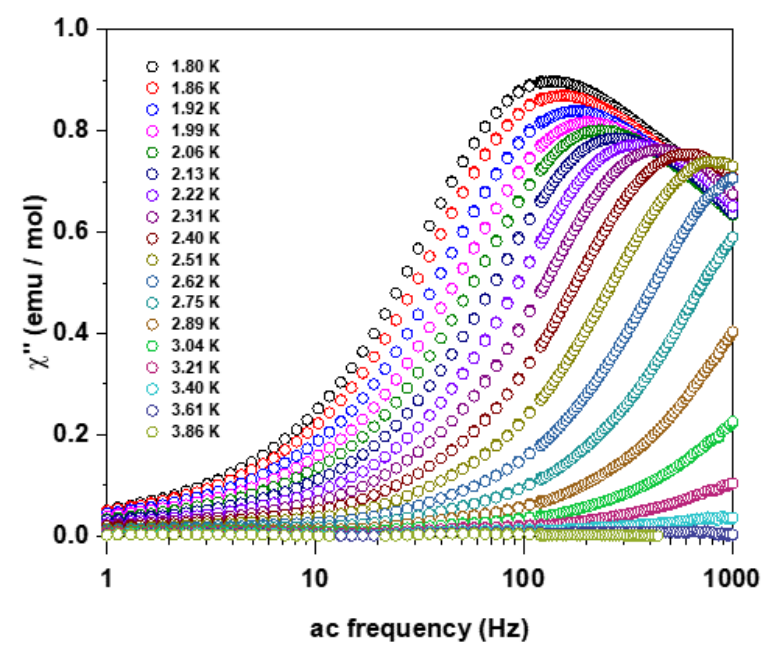

Figure 5. Out-of-phase susceptibility curves for $[\mathbf{B i C N I m}]_{3}\left[\mathbf{D y C l}_{6}\right]$ measured with an $a c$ field of $10 \mathrm{Oe}$ for $10 \mathrm{~Hz}<v<120 \mathrm{~Hz}$ and 2 Oe for $120 \mathrm{~Hz}<v<1000 \mathrm{~Hz}$ under a static $d c$ field of 500 Oe at various temperatures.

The relaxation times were determined from the maxima of the $\chi "=f(v)$ curves (Table S5). These $\tau$ values are consistent with those usually encountered for other SIMs. ${ }^{[56-58]}$ The plot of the relaxation time as a function of temperature can be equally well fitted by a Raman + QTM process $\left(\tau^{-1}=\tau_{Q T M}{ }^{-1}+\mathrm{C} \times T^{\mathrm{n}}\right.$ with $\tau_{Q T M}=1.8(4) \cdot 10^{-3} \mathrm{~s}, C=3(2) \mathrm{s}^{-1} \cdot \mathrm{K}^{-\mathrm{n}}$ and $\left.n=7.9(6)\right)$ or by an 
Orbach + QTM process $\left(\tau^{-1}=\tau_{Q T M}{ }^{-1}+\tau_{0^{-1}} e^{(- \text {UeffT })}\right.$ with $\tau_{Q T M}=1.4(2) \cdot 10^{-3} \mathrm{~s}, \tau_{0}=9(5) \cdot 10^{-8} \mathrm{~s}$ and $U_{\text {eff }}=20(2) \mathrm{K}^{-1}$ ) (Figure 6). The values of the parameters are within the range of values determined for other $\mathrm{Dy}^{3+}$ SIMS in octahedral environment (Table 1). Even though $\mathrm{n}$ should be equal to 9 for a Kramers ion, it can take lower values, down to $n=4 .^{[59-62]}$

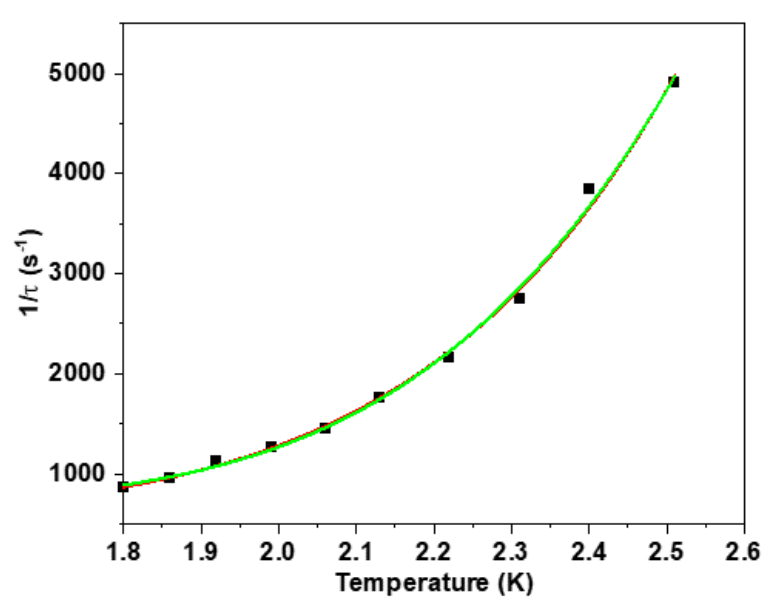

Figure 6. Inverse of the relaxation time as a function of $\mathrm{T}$ (black squares: experimental points, full red line: best fit using Raman + QTM process, full green line: best fit using Orbach + QTM process).

Distinction between Raman and Orbach mechanisms is here rather difficult as the fits are equally good. Due to the very limited temperature range, a fit considering both Orbach and Raman mechanisms is clearly overparametrized. Therefore, the fits were performed considering the two mechanisms separately, along with remaining QTM mechanism, which is not totally suppressed by application of a $d c$ field. Nevertheless, the three mechanisms likely coexist in this temperature range, which is also suggested by the asymmetric distribution of the relaxation rates.

In order to have further insight in the magnetic behaviour, we have examined the structures of compounds showing $\mathrm{Dy}^{3+}$ ions in different octahedral environments (Figure 7 and Table S6) and some characteristic values describing their magnetic behaviours are given in Table $1 .{ }^{[35-43]}$ Since the local geometry influences the magnetic properties, we have limited this research to compounds containing $\mathrm{Dy}^{3+}$ ions surrounded by six ligands in an octahedral geometry (see CShM values in Table 1). As one can observe, the majority of these compounds showing SIM properties tends to exhibit the shorter distances along the axial direction and angle values comprised between $170^{\circ}$ and $180^{\circ}$. When the compounds exhibit an equatorial crystal field with the four shortest distances in the equatorial plane (see for example third line in Figure 7), almost 
no compound exhibits SIM behaviour. Beyond consideration of the local symmetry, it seems that coordination of halides with decreasing electronegativity in the equatorial plane generates increasing values of $U_{\text {eff }}$ (i.e. longer bond length and weaker ligand field, see for example first line in Figure 7). These observations are in agreement with the assumption that oblate electron densities would be more efficient for SIM properties with axial ligand fields. ${ }^{[5,4,63]}$

Concerning the nature of the mechanisms involved in the relaxation of the magnetization for these compounds, it can be noticed that QTM mechanism is not suppressed and that Orbach and Raman processes are both suggested in numerous cases.

Table 1. Nature of atoms constituting the first coordination sphere, values of the deviation from an ideal octahedron, relaxation time for QTM ( $\left.\tau_{\mathrm{QTM}}\right)$, effective energy barrier $\left(\mathrm{U}_{\mathrm{eff}}\right)$, relaxation rate $\left(\tau_{0}\right)$, values of $\mathrm{n}$ and $\mathrm{C}$ for Raman process, additional $d c$ field used for the $a c$ measurements of different mononuclear compounds containing $\mathrm{Dy}^{3+}$ ions in octahedral environment.

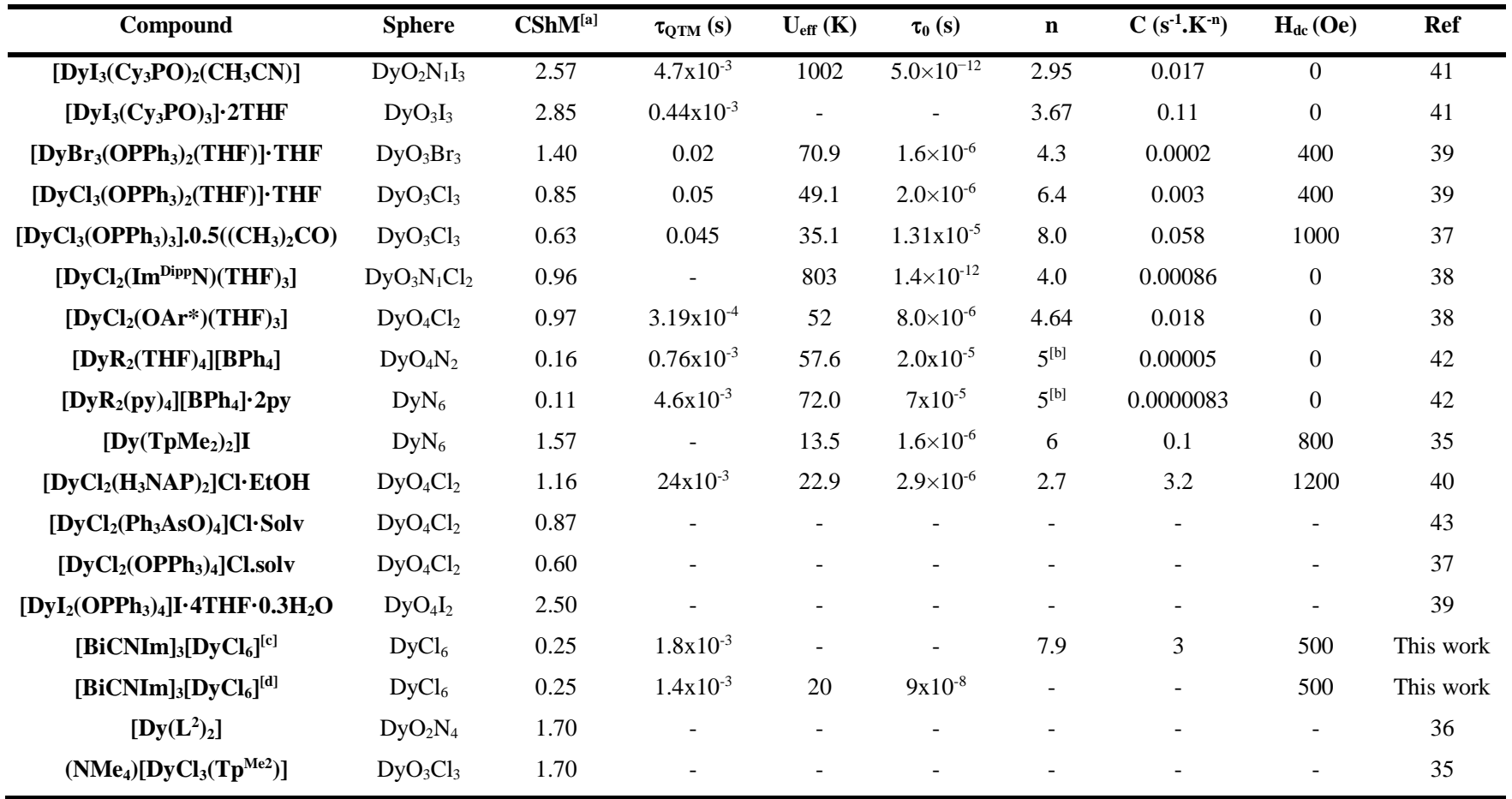

[a] Minimal value determined for OC-6 or Oh geometry from the CShM calculation. [b] Fixed value during the fit of the data. [c] Values determined from the fit using Raman + QTM process. [d] Values determined from the fit using Orbach + QTM process. 


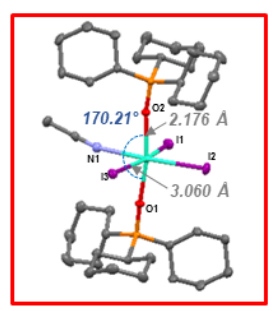

$\left[\mathrm{Dyl}_{3}\left(\mathrm{Cy}_{3} \mathrm{PO}\right)_{2}\left(\mathrm{CH}_{3} \mathrm{CN}\right)\right]$ Ref 41

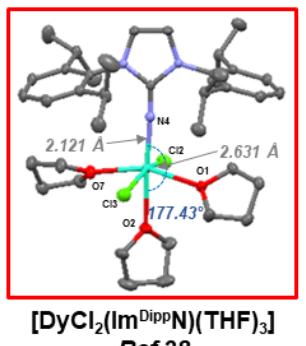

Ref 38

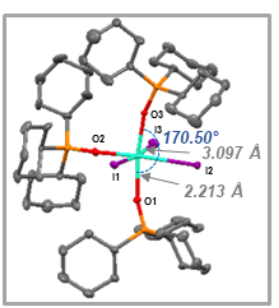

$\left[\mathrm{Dyl}_{3}\left(\mathrm{Cy}_{3} \mathrm{PO}\right)_{3}\right] \cdot 2 \mathrm{THF}$ Ref 41

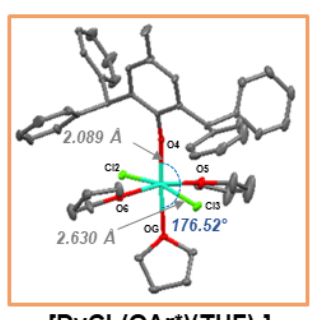

$\left[\mathrm{DyCl}_{2}\left(\mathrm{OAr}^{*}\right)(\mathrm{THF})_{3}\right]$

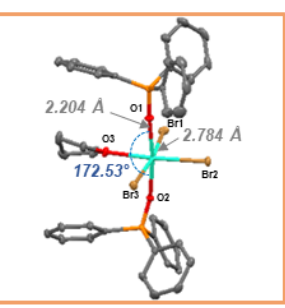

$\left[\mathrm{DyBr}_{3}\left(\mathrm{OPPh}_{3}\right)_{2}(\mathrm{THF})\right] \cdot \mathrm{THF}$ Ref 39

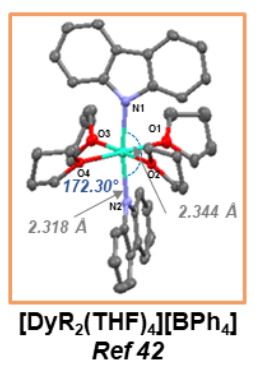

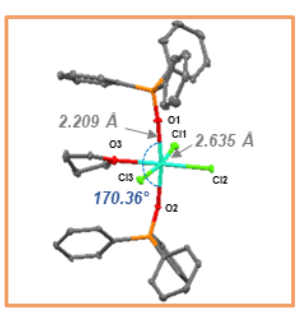

$\left[\mathrm{DyCl}_{3}\left(\mathrm{OPPh}_{3}\right)_{2}(\mathrm{THF})\right] \cdot \mathrm{THF} \quad\left[\mathrm{DyCl}_{3}\left(\mathrm{OPPh}_{3}\right)_{3}\right] \cdot 0.5\left(\left(\mathrm{CH}_{3}\right)_{2} \mathrm{CO}\right)$ Ref 39

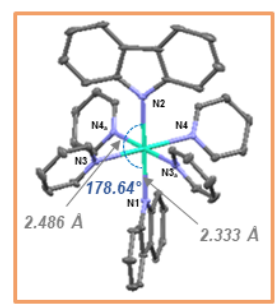

$\left[D^{2} R_{2}(p y)_{4}\right]\left[B P h_{4}\right] \cdot 2 p y$ Ref 42

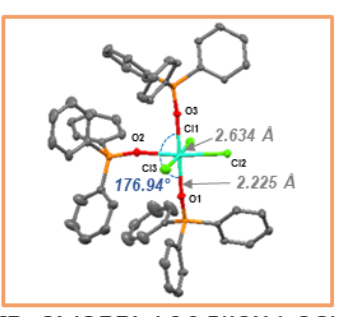

Ref 37

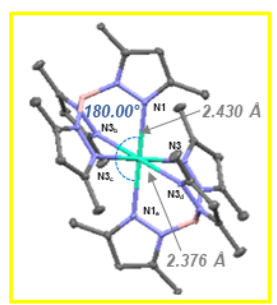

[Dy $\left.\left(\mathrm{TpMe}_{2}\right)_{2}\right]$

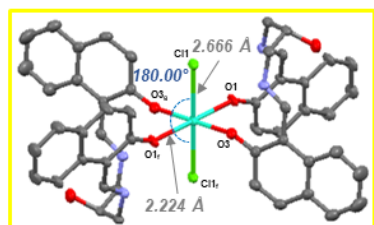
$\left[\mathrm{DyCl}_{2}\left(\mathrm{H}_{3} \mathrm{NAP}\right)_{2}\right] \mathrm{Cl} \cdot \mathrm{EtOH}$
$\operatorname{Ref} 40$

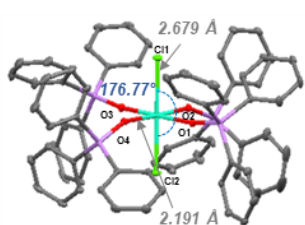

[DyCl $\left.{ }_{2}\left(\mathrm{Ph}_{3} \mathrm{AsO}\right)_{4}\right] \mathrm{Cl} \cdot$ Solv Ref 43

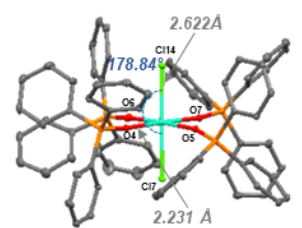

[DyCl $\left.2\left(\mathrm{OPPh}_{3}\right)_{4}\right]$ Cl.solv

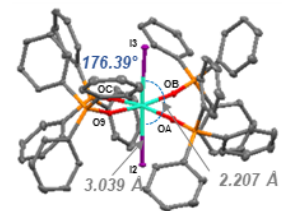

$\left.\left[\mathrm{Dyl}_{2}(\mathrm{OPPh})_{4}\right)_{4}\right] \cdot 4 \mathrm{THF} \cdot 0.3 \mathrm{H}_{2} \mathrm{O}$ Ref 39
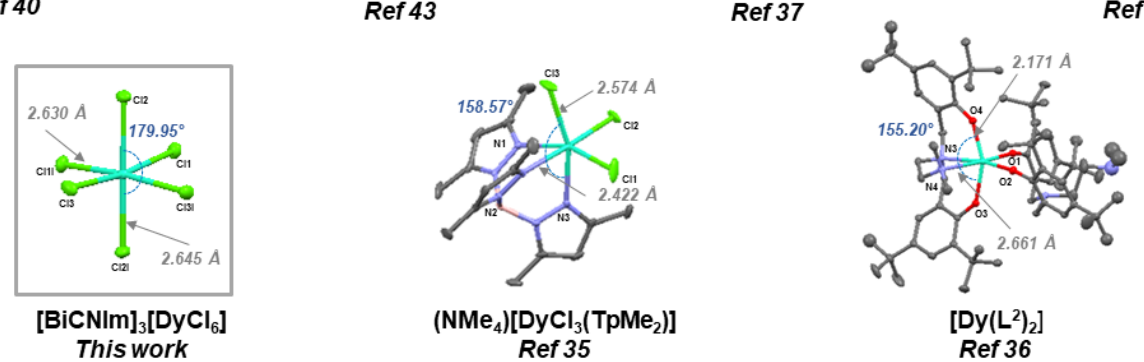

Figure 7. Representation of different octahedral environments observed in mononuclear Dy ${ }^{3+}$ based compounds (dysprosium in cyan, carbon in grey, oxygen in red, nitrogen in blue, phosphorus in orange, chloride in green, bromide in brown, iodide in violet, boron in pink). Values of shorter and longer distances as well as axial angle have been indicated on this figure (for more details, see table S6). Coloured frames indicate the compounds for which the SIM behaviour has been observed and their colour is related to the values of $U_{\text {eff: }}$ red for large values

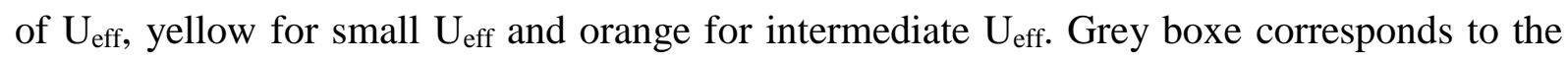
title compound exhibiting equivalent Raman + QTM mechanisms and Orbach + QTM mechanisms (see table 1). 


\section{Theoretical study}

To probe the electronic structure and the magnetic anisotropy of the title compound [BiCNIm $]_{3}\left[\mathbf{D y C l}_{6}\right]$, ab initio calculations have been performed using the SO-CASSCF method. It has been shown for octahedral $f$ complexes that the ligand field can be written as following: ${ }^{[64]}$

$$
\widehat{V}_{C F}=W\left[x \frac{\hat{o}_{4}}{F(4)}+(1-|x|) \frac{\hat{o}_{6}}{F(6)}\right]
$$

with $\hat{O}_{4}=\hat{O}_{4}^{0}(J)+5 \hat{O}_{4}^{4}(J)$ and $\hat{O}_{6}=\hat{O}_{6}^{0}(J)-215 \hat{O}_{6}^{4}(J), \hat{O}_{k}^{q}(J)$ are the Stevens operators for the $J$ manifold, $\mathrm{F}(4)$ and $\mathrm{F}(6)$ are factors dependent of the $\mathrm{J}$ value, $x$ and $W$ are two adjustable parameters, $W$ defining the energy scale and $x$ the ratio between the fourth and the sixth orders. To understand the influence of the symmetry, the SO-CASSCF calculations have been realized considering first an idealized case formed by a symmetrized $\left[\mathrm{DyCl}_{6}\right]^{3-}$ octahedral structure and then the X-ray structure. Details for these calculations are reported in computational details and in SI part. Figure 8 gives the calculated $a b$ initio energies and the corresponding $g$ factors for the symmetrized and crystal structures. The splitting of the ground $J$ manifold is about $300 \mathrm{~cm}^{-}$ ${ }^{1}$. In the symmetrized structure, the ground state is an isotropic Kramers doublet with a $\mathrm{g}$ factor of 6.62 (Figure 8). The first excited quartet lies at $21 \mathrm{~cm}^{-1}$ and then a Kramers doublet at $98 \mathrm{~cm}^{-}$ 1 . This ordering of the states corresponds to Eq. 1 with negative $W$ and $x$. Only the crystal field parameters $B_{0}^{4}, B_{4}^{4}, B_{0}^{6}$ and $B_{4}^{6}$ do not vanish (Table $\mathrm{S} 7$ ). The parameter $\mathrm{S}$ allows to evaluate the strength of the ligand field with only one parameter. The $4^{\text {th }}$ order parameter $\mathrm{S}^{4}$ is larger than the $6^{\text {th }}$ order one $S^{6}$ (Table S7), in accordance with the ordering states which implies that $|x|>$ 0.5 .

In the crystal structure, the presence of the $[\mathrm{BiImCN}]^{+}$cation leads to a deformation of the coordination sphere. Consequently, the quartets split into two Kramers doublets by $10 \mathrm{~cm}^{-1}$ and the $g$ tensors are anisotropic. As an example, $g$ values of the ground Kramers doublet range from 5 to 8.6 (Figure 8). With the lowering of the symmetry, all crystal field parameters are non-zero (Table S8), but this barely affects the strength parameters and the response to the magnetic field (magnetic susceptibility). Consequently, the departure from the ideal octahedral symmetry leads to a small anisotropy in the $\mathrm{g}$ tensor of the ground state which can be at the origin of the SIM behaviour. This slight deviation from the ideal octahedral symmetry can also explain the absence of zero-field SIM behaviour and the probability of QTM process.

These observations tend also to indicate that existence of axiality within these octahedral $\mathrm{Dy}^{3+}$ based compounds is not necessary to promote SIM properties since the $\mathrm{Dy}^{3+}$ based compound with a more regular octehadral environment give rise to these properties. From this point of 
view, the possibility to access to new other compounds with more regular geometry and to explore their magnetic behaviour is particularly appealing.

(a)

Symmetrized structure

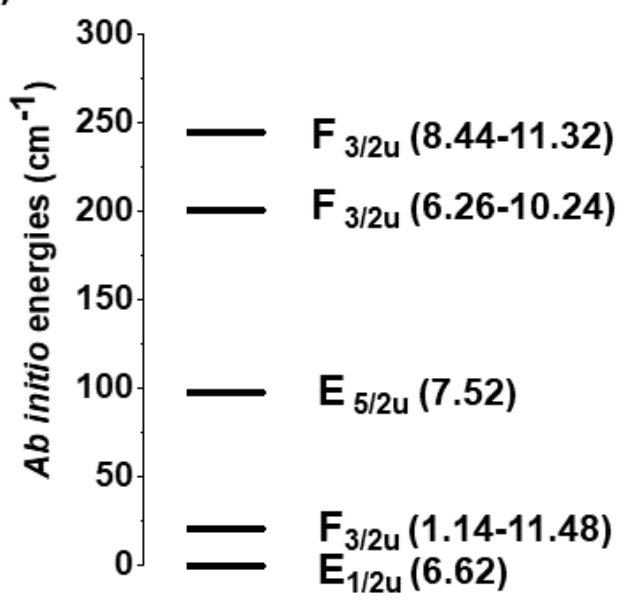

(b)

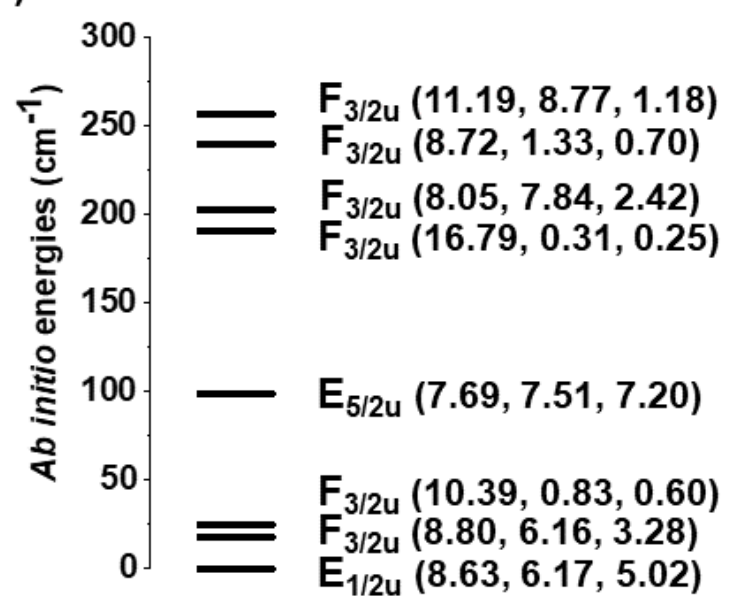

Figure 8. SO-CASSCF energies of the low-lying states and corresponding g-tensor values (in bracket) calculated (a) for the symmetrized $\left[\mathrm{DyCl}_{6}\right]^{3-}$ structure and (b) for the X-ray structure of $[\mathrm{BiCNIm}]_{3}\left[\mathrm{DyCl}_{6}\right]$.

\section{Conclusion}

We have reported the synthesis and the characterization of a new compound containing Dy ${ }^{3+}$ ions in an unusual octahedral hexachloride environment. Despite its sensitivity to air, we have been able to investigate its photoluminescent and magnetic properties. The analysis of the experimental magnetic features indicates that $\left[\mathbf{B i C N I m}_{3}\left[\mathbf{D y C l}_{\mathbf{6}}\right]\right.$ exhibits SIM properties for which the relaxation mechanism involves Raman, Orbach and QTM mechanisms. In contrast with previous examples where sophisticated ligands are employed to generate an octahedral environment, this work illustrates the possibility offered by imidazolium ionic liquid to stabilize octahedral $\left[\mathrm{DyCl}_{6}\right]^{3-}$ units. This result paves the way to the synthesis of new series of lanthanide based SIMs involving other lanthanide salts with the possibility to vary the imidazolium ILs that can be modified with different substitutions of the cationic or the anionic part.

\section{Experimental Section}

\section{Materials and general methods}

Chloroacetonitrile, trimethylsilylimidazole and $\mathrm{DyCl}_{3} \cdot 6 \mathrm{H}_{2} \mathrm{O}$ were purchased from Alfa Aesar. They were used as received. Elemental analyses for $\mathrm{C}, \mathrm{H}, \mathrm{N}$ were performed at the Service de 
Microanalyses of the Institut de Chimie de Strasbourg. NMR spectra in solution were recorded using a Bruker AVANCE 300 spectrometer. FTIR spectra were performed on a Perkin Elmer Spectrum Two UATR-FTIR spectrometer. The powder XRD patterns were collected with a Bruker D8 diffractometer using a copper $\mathrm{K} \alpha_{1}$ radiation $(\lambda=1.540598 \AA)$. The SEM images were obtained with a JEOL 6700F scanning electron microscope (SEM) equipped with a field emission gun (FEG), operating at $15 \mathrm{kV}$ in the composition mode of the instrument. TGA-TDA experiments were performed using a TA instrument SDT Q600 (heating rates of $5{ }^{\circ} \mathrm{C} \cdot \mathrm{min}^{-1}$ under air stream).

\section{Synthesis of the 1,3-bis((cyanomethyl)imidazolium) chloride [BiCNIm][CI]}

The imidazolium salt was synthesized according to protocol adapted from the literature. ${ }^{[65,66]}$ Chloroacetonitrile $(1.38 \mathrm{~mL}, 22 \mathrm{mmol})$ and trimethylsilylimidazole $(1.46 \mathrm{~mL}, 10 \mathrm{mmol})$ were mixed in a round bottom flask. The mixture was stirred and heated at $333 \mathrm{~K}$ for 24 hours. After cooling at room temperature, the brown mixture is washed with diethyl ether $(3 \times 10 \mathrm{~mL})$. The white solid is dried under vacuum. The yield of the reaction is around $75 \%$.

Elemental analysis for $\mathrm{C}_{7} \mathrm{H}_{7} \mathrm{~N}_{4} \mathrm{Cl} \cdot 0.25 \mathrm{H}_{2} \mathrm{O}\left(M=187.0\right.$ g.mol $\left.{ }^{-1}\right)$ Found (Calc) (\%): C 45.36 (44.92), H 4.01 (4.01), N 30.30 (29.95). ${ }^{1} \mathrm{H}$ NMR ( $\left.\mathrm{D}_{2} \mathrm{O}\right): \delta$ (ppm) $=7.75$ (s, 2), 5.45 (s, 4). ${ }^{13} \mathrm{C}$ $\operatorname{NMR}\left(\mathrm{D}_{2} \mathrm{O}\right): \delta(\mathrm{ppm})=138.2,123.5,113.4,37.5$. IR (reflectance, $\left.\mathrm{cm}^{-1}\right): 3187(\mathrm{~m}), 3136(\mathrm{w})$, 3097 (w), 3008 (s), 2969 (m), 2899 (w), 2260 (w), 1806 (w), 1761 (w), 1684 (m), 1563 (s), 1428 (m), 1390 (s), 1345 (m), 1294 (m), 1256 (m), 1180 (s), 1110 (m), 1033 (w), 931 (m), 873 (s), $796(\mathrm{~s}), 719(\mathrm{~m}), 611(\mathrm{~s}), 521(\mathrm{~m}), 463(\mathrm{w})$.

\section{Synthesis of [BiCNIm $]_{3}\left[\mathrm{DyCl}_{6}\right]$}

[BiCNIm] [Cl] $(90 \mathrm{mg}, 0.50 \mathrm{mmol})$ and $\mathrm{DyCl}_{3} \cdot 6 \mathrm{H}_{2} \mathrm{O}(94 \mathrm{mg}, 0.25 \mathrm{mmol})$ were introduced in 6 $\mathrm{mL}$ of acetonitrile. The mixture was sealed in a Teflon-lined stainless steel bomb $(23 \mathrm{~mL})$ and heated at $363 \mathrm{~K}$ for 2 days. After cooling at room temperature, colorless crystals were obtained. They were filtered and washed with ethanol. The yield of the reaction is around $33 \%$.

Elemental analysis for $\mathrm{C}_{21} \mathrm{H}_{21} \mathrm{~N}_{12} \mathrm{Cl}_{6} \mathrm{Dy}_{1}\left(M=816.5\right.$ g.mol $\left.{ }^{-1}\right)$ Found (Calc) (\%): C 33.69 (33.94), H 3.01 (2.83), N 22.38 (22.63). IR (reflectance, $\mathrm{cm}^{-1}$ ): 3365 (sh), 3129 (w), 3104 (w), 3065 (m), 2969 (m), 2924 (w), 1622 (w), 1544 (s), 1435 (w), 1396 (w), 1345 (w), 1313 (w), $1256(\mathrm{w}), 1212(\mathrm{w}), 1174(\mathrm{~s}), 1110(\mathrm{~m}), 1020$ (w), $918(\mathrm{~m}), 876(\mathrm{w}), 835$ (m), 745 (s), 617 (s), 484 (sh).

\section{Physical measurements}

X-ray measurements. Single crystal X-ray diffraction measurement was carried out at room temperature using a Kappa Nonius CCD diffractometer. The diffraction intensities were 
collected with graphite-monochromatized Mo K $\alpha$ radiation $(\lambda=0.71073 \AA)$. Intensity data were corrected for Lorenz-polarization and absorption factors. The structure was solved by direct methods using SIR92, ${ }^{[67]}$ and refined against $F^{2}$ by full-matrix least-squares methods using SHELXL-2018/3 ${ }^{[68]}$ with anisotropic displacement parameters for all non-hydrogen atoms. All calculations were performed by using the Crystal Structure crystallographic software package WINGX. ${ }^{[69]}$ The structures were represented with Mercury. ${ }^{[70]}$ All hydrogen atoms were introduced into the calculations as a riding model with isotropic thermal parameters.

Magnetic measurements. The magnetic measurements were conducted using a Quantum Design MPMS-3 magnetometer. The static susceptibility measurements were performed in the $1.8 \mathrm{~K}-300 \mathrm{~K}$ temperature range with an applied field of 0.5 T. Samples were blocked in eicosane to avoid orientation under magnetic field. Magnetization measurements at different fields and at given temperature confirm the absence of ferromagnetic impurities. Data were corrected for the sample holder and eicosane and diamagnetism was estimated from Pascal constants.

Photoluminescence and photoluminescence excitation. These measurements were performed using a broad-spectrum Energetiq ${ }^{\circledR}$ EQ-99FC laser-driven light source (LDLS ${ }^{\mathrm{TM}}$ ) spectrally filtered by a monochromator. The PL signal was dispersed in a spectrometer and detected by a cooled charge coupled device (CCD) camera.

\section{Computational details}

Calculations were performed using the MOLCAS-7.8 suite of software, on the $\left[\mathrm{DyCl}_{6}\right]^{3-}$ complex for the X-rays geometry and a symmetrized octahedral structure with a Dy-Cl distance of $2.64 \AA$. Relativistically contracted ANO-RCC basis sets of TZP quality were used. ${ }^{[71,72]}$ Firstly, a SF-CASSCF (spin-free CASSCF) calculation was performed ${ }^{[73]}$ with an active space composed of the seven $4 \mathrm{f}$ orbitals of the lanthanide ion and associated electrons, that is, CAS(9,7). Spin-orbit (SO) coupling was included by a state interaction with the RASSI (restricted active space state interaction) method. ${ }^{[74]} 21$ sextets and 108 quartets were considered for the state interaction. Scalar relativistic effects were taken into account by means of the Douglas-Kroll-Hess transformation, ${ }^{[75]}$ and the SO integrals were calculated by using the AMFI (atomic mean-field integrals) approximation. g-values were calculated according to reference $^{[76]}$ and CFPs were calculated with a local program written in Mathematica as described in references. ${ }^{[77,78]}$

Deposition Number $\mathbf{2 0 4 5 4 3 5}$ (for [BiCNIm] $]_{3}\left[\mathbf{D y C l}_{6}\right]$ ) contains the supplementary crystallographic data for this paper. These data are provided free of charge by the joint Cambridge Crystallographic Data Centre and Fachinformationszentrum Karlsruhe Access Structures service www.ccdc.cam.ac.uk/structures. 


\section{Acknowledgements}

The authors thank the Centre National de la Recherche Scientifique (CNRS), the Université de Strasbourg (Idex), the Labex NIE (ANR-11-LABX-0058-NIE within the Investissement d'Avenir program ANR-10-IDEX-0002-02) for funding. Nesrine Benamara thanks the program Profas $\mathrm{B}^{+}$of Campus France for the grant of her $\mathrm{PhD}$ and the Direction Générale de la Recherche Scientifique et du Développement Technologique (DGRSDT). The authors are grateful to Didier Burger for technical assistance.

\section{Conflict of Interest}

The authors declare no conflict of interest.

\section{References}

[1] R. Sessoli, D. Gatteschi, A. Caneschi, M. A. Novak, Nature 1993, 365, 141-143.

[2] T. Komeda, K. Katoh, M. Yamashita, in Mol. Technol., John Wiley \& Sons, Ltd, 2019, pp. 263-304.

[3] A. Cornia, M. Mannini, R. Sessoli, D. Gatteschi, Eur. J. Inorg. Chem. 2019, 2019, 552568.

[4] L. Ungur, L. F. Chibotaru, Inorg. Chem. 2016, 55, 10043-10056.

[5] S. G. McAdams, A.-M. Ariciu, A. K. Kostopoulos, J. P. S. Walsh, F. Tuna, Coord. Chem. Rev. 2017, 346, 216-239.

[6] H. L. C. Feltham, S. Brooker, Coord. Chem. Rev. 2014, 276, 1-33.

[7] D. N. Woodruff, R. E. P. Winpenny, R. A. Layfield, Chem. Rev. 2013, 113, 5110-5148.

[8] L. Bogani, W. Wernsdorfer, Nat. Mater. 2008, 7, 179-186.

[9] A. Ardavan, O. Rival, J. J. L. Morton, S. J. Blundell, A. M. Tyryshkin, G. A. Timco, R. E. P. Winpenny, Phys. Rev. Lett. 2007, 98, 057201.

[10] M. N. Leuenberger, D. Loss, Nature 2001, 410, 789-793.

[11] G. Christou, D. Gatteschi, D. N. Hendrickson, R. Sessoli, MRS Bull. 2000, 25, 66-71.

[12] D. Mitcov, A. H. Pedersen, M. Ceccato, R. M. Gelardi, T. Hassenkam, A. Konstantatos, A. Reinholdt, M. A. Sørensen, P. W. Thulstrup, M. G. Vinum, F. Wilhelm, A. Rogalev, W. Wernsdorfer, E. K. Brechin, S. Piligkos, Chem. Sci. 2019, 10, 3065-3073.

[13] E. Kiefl, M. Mannini, K. Bernot, X. Yi, A. Amato, T. Leviant, A. Magnani, T. Prokscha, A. Suter, R. Sessoli, Z. Salman, ACS Nano 2016, 10, 5663-5669. 
[14] M. Mannini, P. Sainctavit, R. Sessoli, C. Cartier dit Moulin, F. Pineider, M.-A. Arrio, A. Cornia, D. Gatteschi, Chem. Eur. J. 2008, 14, 7530-7535.

[15] L. Bogani, L. Cavigli, M. Gurioli, R. L. Novak, M. Mannini, A. Caneschi, F. Pineider, R. Sessoli, M. Clemente-León, E. Coronado, A. Cornia, D. Gatteschi, Adv. Mater. 2007, 19, 39063911.

[16] K. Bader, D. Dengler, S. Lenz, B. Endeward, S.-D. Jiang, P. Neugebauer, J. van Slageren, Nat. Commun. 2014, 5, 5304.

[17] A. Candini, G. Lorusso, F. Troiani, A. Ghirri, S. Carretta, P. Santini, G. Amoretti, C. Muryn, F. Tuna, G. Timco, E. J. L. McInnes, R. E. P. Winpenny, W. Wernsdorfer, M. Affronte, Phys. Rev. Lett. 2010, 104, 037203.

[18] A. Wilson, S. Hill, R. S. Edwards, N. Aliaga-Alcalde, G. Christou, AIP Conf. Proc. 2006, 850, 1141-1142.

[19] S. Hill, R. S. Edwards, N. Aliaga-Alcalde, G. Christou, Science 2003, 302, 1015-1018.

[20] S.-G. Wu, Y.-Y. Peng, Y.-C. Chen, J.-L. Liu, M.-L. Tong, Dalton Trans. 2020, 49, 1414014147.

[21] C. Zhang, X. Ma, P. Cen, X. Jin, J. Yang, Y.-Q. Zhang, J. Ferrando-Soria, E. Pardo, X. Liu, Dalton Trans. 2020, 49, 14123-14132.

[22] D. Maniaki, E. Pilichos, S. P. Perlepes, Front. Chem. 2018, 6, 1-28.

[23] K. S. Pedersen, J. Bendix, R. Clérac, Chem. Commun. 2014, 50, 4396-4415.

[24] M. Nakano, H. Oshio, Chem. Soc. Rev. 2011, 40, 3239-3248.

[25] K. Najafi, A. L. Wysocki, K. Park, S. E. Economou, E. Barnes, J. Phys. Chem. Lett. 2019, $10,7347-7355$.

[26] N. Ishikawa, M. Sugita, T. Ishikawa, S. Koshihara, Y. Kaizu, J. Am. Chem. Soc. 2003, 125, $8694-8695$.

[27] A. Arauzo, L. Gasque, S. Fuertes, C. Tenorio, S. Bernès, E. Bartolomé, Dalton Trans. 2020, 49, 13671-13684.

[28] C. D. Buch, D. Mitcov, S. Piligkos, Dalton Trans. 2020, 49, 13557-13565.

[29] M. Kong, X. Feng, J. Li, Z.-B. Hu, J. Wang, X.-J. Song, Z.-Y. Jing, Y.-Q. Zhang, Y. Song, Dalton Trans. 2020, 49, 14931-14940..

[30] S. K. Gupta, R. Murugavel, Chem. Commun. 2018, 54, 3685-3696.

[31] J.-L. Liu, Y.-C. Chen, M.-L. Tong, Chem. Soc. Rev. 2018, 47, 2431-2453.

[32] M. Feng, M.-L. Tong, Chem. Eur. J. 2018, 24, 7574-7594.

[33] J. Lu, M. Guo, J. Tang, Chem. Asian J. 2017, 12, 2772-2779. 
[34] G. Cucinotta, M. Perfetti, J. Luzon, M. Etienne, P.-E. Car, A. Caneschi, G. Calvez, K. Bernot, R. Sessoli, Angew. Chem. Int. Ed. 2012, 51, 1606-1610; Angew. Chem. 2012, 124, $1638-1642$.

[35] D. I. Alexandropoulos, K. R. Vignesh, H. Xie, K. R. Dunbar, Dalton Trans. 2019, 48, 10610-10618.

[36] M. Guo, J. Tang, Inorganics 2018, 6, 16.

[37] S. K. Langley, K. R. Vignesh, K. Holton, S. Benjamin, G. B. Hix, W. Phonsri, B. Moubaraki, K. S. Murray, G. Rajaraman, Inorganics 2018, 6, 61.

[38] B.-C. Liu, N. Ge, Y.-Q. Zhai, T. Zhang, Y.-S. Ding, Y.-Z. Zheng, Chem. Commun. 2019, $55,9355-9358$.

[39] K. R. Vignesh, D. I. Alexandropoulos, H. Xie, K. R. Dunbar, Dalton Trans. 2020, 49, 4694-4698.

[40] S. Yu, Z. Chen, H. Hu, B. Li, Y. Liang, D. Liu, H. Zou, D. Yao, F. Liang, Dalton Trans. 2019, 48, 16679-16686.

[41] M. Li, H. Wu, Z. Xia, L. Ungur, D. Liu, L. F. Chibotaru, H. Ke, S. Chen, S. Gao, Inorg. Chem. 2020, 59, 7158-7166.

[42] J. Long, A. N. Selikhov, E. Mamontova, K. A. Lyssenko, Y. Guari, J. Larionova, A. A. Trifonov, Dalton Trans. 2020, 49, 4039-4043.

[43] M. Fondo, J. Corredoira-Vázquez, A. M. García-Deibe, J. Sanmartín- Matalobos, J. M. Herrera, E. Colacio, Front. Chem. 2018, 6, DOI 10.3389/fchem.2018.00420.

[44] M. Gregson, N. F. Chilton, A.-M. Ariciu, F. Tuna, I. F. Crowe, W. Lewis, A. J. Blake, D. Collison, E. J. L. McInnes, R. E. P. Winpenny, S. T. Liddle, Chem. Sci. 2015, 7, 155-165.

[45] J.-L. Liu, K. Yuan, J.-D. Leng, L. Ungur, W. Wernsdorfer, F.-S. Guo, L. F. Chibotaru, M.L. Tong, Inorg. Chem. 2012, 51, 8538-8544.

[46] K. Binnemans, Chem. Rev. 2009, 109, 4283-4374.

[47] J. Alvarez-Vicente, S. Dandil, D. Banerjee, H. Q. N. Gunaratne, S. Gray, S. Felton, G. Srinivasan, A. M. Kaczmarek, R. Van Deun, P. Nockemann, J. Phys. Chem. B 2016, 120, 53015311.

[48] Y. Han, C. Lin, Q. Meng, F. Dai, A. G. Sykes, M. T. Berry, P. S. May, Inorg. Chem. 2014, $53,5494-5501$.

[49] C. C. Hines, D. B. Cordes, S. T. Griffin, S. I. Watts, V. A. Cocalia, R. D. Rogers, New J. Chem. 2008, 32, 872-877.

[50] M. Pinsky, D. Avnir, Inorg. Chem. 1998, 37, 5575-5582.

[51] J. Rodriguez-Carvajal, Phys. Condens. Matter 1993, 192, 55-69. 
[52] A. B. Ruiz-Muelle, A. García-García, A. A. García-Valdivia, I. Oyarzabal, J. Cepeda, J. M. Seco, E. Colacio, A. Rodríguez-Diéguez, I. Fernández, Dalton Trans. 2018, 47, 1278312794.

[53] C. Benelli, D. Gatteschi, Chem. Rev. 2002, 102, 2369-2388.

[54] K. S. Cole, R. H. Cole, J. Chem. Phys. 1941, 9, 341-351.

[55] D. Gatteschi, R. Sessoli, J. Villain, Molecular Nanomagnets, Oxford University Press, 2006.

[56] C. Y. Chow, H. Bolvin, V. E. Campbell, R. Guillot, J. W. Kampf, W. Wernsdorfer, F. Gendron, J. Autschbach, V. L. Pecoraro, T. Mallah, Chem. Sci. 2015, 6, 4148-4159.

[57] V. E. Campbell, R. Guillot, E. Riviere, P.-T. Brun, W. Wernsdorfer, T. Mallah, Inorg. Chem. 2013, 52, 5194-5200.

[58] A. Baniodeh, Y. Lan, G. Novitchi, V. Mereacre, A. Sukhanov, M. Ferbinteanu, V. Voronkova, C. E. Anson, A. K. Powell, Dalton Trans. 2013, 42, 8926-8938.

[59] F. Pointillart, J.-K. Ou-Yang, G. Fernandez Garcia, V. Montigaud, J. Flores Gonzalez, R. Marchal, L. Favereau, F. Totti, J. Crassous, O. Cador, L. Ouahab, B. Le Guennic, Inorg. Chem. 2019, 58, 52-56.

[60] K. N. Shrivastava, Phys. Status Solidi B 1983, 117, 437-458.

[61] A. Singh, K. N. Shrivastava, Phys. Status Solidi B 1979, 95, 273-277.

[62] P. L. Scott, C. D. Jeffries, Phys. Rev. 1962, 127, 32-51.

[63] J. D. Rinehart, J. R. Long, Chem. Sci. 2011, 2, 2078-2085.

[64] K. R. Lea, M. J. M. Leask, W. P. Wolf, J. Phys. Chem. Solids 1962, 23, 1381-1405.

[65] Z. Fei, D. Zhao, D. Pieraccini, W. H. Ang, T. J. Geldbach, R. Scopelliti, C. Chiappe, P. J. Dyson, Organometallics 2007, 26, 1588-1598.

[66] D. Zhao, Z. Fei, R. Scopelliti, P. J. Dyson, Inorg. Chem. 2004, 43, 2197-2205.

[67] A. Altomare, G. Cascarano, C. Giacovazzo, A. Guagliardi, M. C. Burla, G. Polidori, M. Camalli, J. Appl. Crystallogr. 1994, 27, 435.

[68] G. Sheldrick, Acta Crystallogr. Sect. A 2008, 64, 112-122.

[69] L. Farrugia, J. Appl. Crystallogr. 1999, 32, 837-838.

[70] P. R. Edgington, P. McCabe, C. F. Macrae, E. Pidcock, G. P. Shields, R. Taylor, M. Towler, J. Van De Streek, J. Appl. Crystallogr. 2006, 39, 453-457.

[71] B. O. Roos, R. Lindh, P.-Å. Malmqvist, V. Veryazov, P.-O. Widmark, J. Phys.Chem. A 2004, 108, 2851-2858.

[72] B. O. Roos, R. Lindh, P.-Å. Malmqvist, V. Veryazov, P.-O. Widmark, Chem. Phys. Lett. 2005, 409, 295-299. 
[73] B. O. Roos, P. R. Taylor, P. E. M. Sigbahn, Chem. Phys. 1980, 48, 157-173.

[74] P. Å. Malmqvist, B. O. Roos, B. Schimmelpfennig, Chem. Phys. Lett. 2002, 357, 230-240.

[75] B. A. Hess, Phys. Rev. A 1986, 33, 3742-3748.

[76] H. Bolvin, ChemPhysChem 2006, 7, 1575-1589.

[77] J. Jung, M. A. Islam, V. L. Pecoraro, T. Mallah, C. Berthon, H. Bolvin, Chem. Eur. J. 2019, 25, 15112-15122.

[78] L. Ungur, L. F. Chibotaru, Chem. Eur. J. 2017, 23, 3708-3718. 


\section{SI part}

\section{Octahedral Hexachloro Environment of $\mathrm{Dy}^{3+}$ with Slow Magnetic Relaxation and Luminescent Properties}

Dr. Nesrine Benamara, ${ }^{[a, b]}$ Dr. Mayoro Diop, ${ }^{[a]}$ Cédric Leuvrey, ${ }^{[a]}$ Dr. Marc Lenertz, ${ }^{[a]}$ Dr. Pierre Gilliot, ${ }^{[\mathrm{a}]}$ Mathieu Gallart, ${ }^{[\mathrm{a}]}$ Dr. Hélène Bolvin, ${ }^{[\mathrm{c}]}$ Dr. Fatima Setifi, ${ }^{[\mathrm{b}]}$ Dr. Guillaume Rogez ${ }^{[a]}$ Dr. Pierre Rabu, ${ }^{[\mathrm{a}]}$ Dr. Emilie Delahaye* ${ }^{[\mathrm{a}, \mathrm{d}]}$

a. Université de Strasbourg, CNRS, Institut de Physique et Chimie des Matériaux de Strasbourg, UMR 7504, 67034 Strasbourg, France.

b. Laboratoire de Chimie, Ingénierie Moléculaire et Nanostructures (LCIMN), Université Ferhat Abbas Sétif 1, Sétif 19000, Algeria.

c. Laboratoire de Chimie et de Physique Quantiques, Université de Toulouse and CNRS, 31062 Toulouse, France.

d. Present address: CNRS, Laboratoire de Chimie de Coordination, 205 route de Narbonne, 31077 Toulouse, France and Université de Toulouse, UPS, INPT, LCC, 31077 Toulouse, France.

Table S1. Selected crystallographic data from single crystal for the compound $[\mathrm{BiCNIm}]_{3}\left[\mathrm{DyCl}_{6}\right]$.

\begin{tabular}{|c|c|}
\hline Compound & {$\left[\mathrm{BiCNIm}_{3}\left[\mathrm{DyCl}_{6}\right]\right.$} \\
\hline Formula & $\mathrm{C}_{21} \mathrm{H}_{21} \mathrm{~N}_{12} \mathrm{Cl}_{6} \mathrm{Dy}_{1}$ \\
\hline$M_{r}\left(\mathrm{~g} \cdot \mathrm{mol}^{-1}\right)$ & 816.70 \\
\hline Crystal system & orthorhombic \\
\hline Space group & Pbcn \\
\hline$a(\AA)$ & $13.144(2)$ \\
\hline$b(\AA)$ & $12.098(3)$ \\
\hline$c(\AA)$ & $19.868(2)$ \\
\hline$\alpha\left(^{\circ}\right)$ & 90 \\
\hline$\beta\left(^{\circ}\right)$ & 90 \\
\hline$\gamma\left({ }^{\circ}\right)$ & 90 \\
\hline $\mathrm{V}\left(\AA^{3}\right)$ & 3159 \\
\hline $\mathrm{Z}$ & 4 \\
\hline Temperature $(\mathrm{K})$ & $293(2)$ \\
\hline$D_{\text {calc }}\left(\mathrm{g} \cdot \mathrm{cm}^{-3}\right)$ & 1.717 \\
\hline $\mathrm{F}\left(\begin{array}{llll}0 & 0 & 0\end{array}\right)$ & 1596 \\
\hline $\mathrm{R}_{\text {int }}$ & 0.0568 \\
\hline $\mathrm{S}$ & 1.045 \\
\hline $\mathrm{R} 1[I>2 \sigma(I)]$ & 0.0414 \\
\hline wR2 [all data] & 0.0862 \\
\hline
\end{tabular}



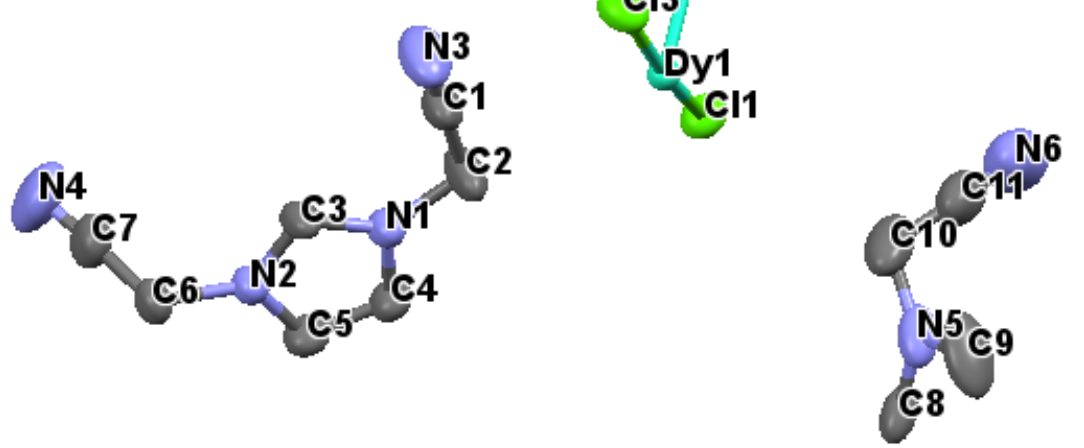

Figure S1. Ellipsoid view of the asymmetric unit of [BiCNIm $]_{3}\left[\mathrm{DyCl}_{6}\right]$.

Table S2. Results of the analysis performed with SHAPE software.

\begin{tabular}{|c|c|c|c|c|}
\hline $\begin{array}{c}\text { Hexagon } \\
\left(D_{6 h}\right)\end{array}$ & $\begin{array}{c}\text { Pentagonal } \\
\text { pyramid } \\
\left(\mathrm{C}_{5 \mathrm{v}}\right)\end{array}$ & $\begin{array}{c}\text { Octahedron } \\
\left(\mathrm{O}_{\mathrm{h}}\right)\end{array}$ & $\begin{array}{c}\text { Trigonal } \\
\text { prism } \\
\left(D_{3 h}\right)\end{array}$ & $\begin{array}{c}\text { Johnson pentagonal } \\
\text { pyramid } \\
\left(\mathrm{C}_{5 \mathrm{v}}\right)\end{array}$ \\
\hline 33.10958 & 27.48737 & 0.24960 & 14.15736 & 31.21085 \\
\hline
\end{tabular}

Table S3. Selected bond distances and angles for [BiCNIm] $]_{3}\left[\mathrm{DyCl}_{6}\right]_{\text {. }}$

\begin{tabular}{|c|c|c|c|}
\hline \multicolumn{2}{|c|}{ Distances [̊] } & \multicolumn{2}{|c|}{ Angles $\left[{ }^{\circ}\right]$} \\
\hline$\overline{\text { Dy1-Cl1 }}$ & $2.6302(12)$ & Cl1-Dy1-Cl1 & $89.30(6)$ \\
\hline Dy1-Cl1 ${ }_{i}$ & $2.6302(12)$ & $\mathrm{Cl1}$ i $-\mathrm{Dy} 1-\mathrm{Cl} 3$ & $89.19(4)$ \\
\hline Dy1-Cl2 & $2.6446(10)$ & Cl3-Dy1-Cl3i & $93.08(6)$ \\
\hline Dy1-Cl2i & $2.6447(10)$ & $\mathrm{Cl} 3{ }_{\mathrm{i}}-\mathrm{Dy} 1-\mathrm{Cl} 1$ & $89.19(4)$ \\
\hline Dy1-Cl3 & $2.6452(12)$ & Cl2-Dy1-Cl2 & $179.95(5)$ \\
\hline Dy1-Cl3 & $2.6452(12)$ & Cl1-Dy1-Cl2 & $85.78(4)$ \\
\hline
\end{tabular}

Symmetry code (i) 1-x, y, 1/2-z. 


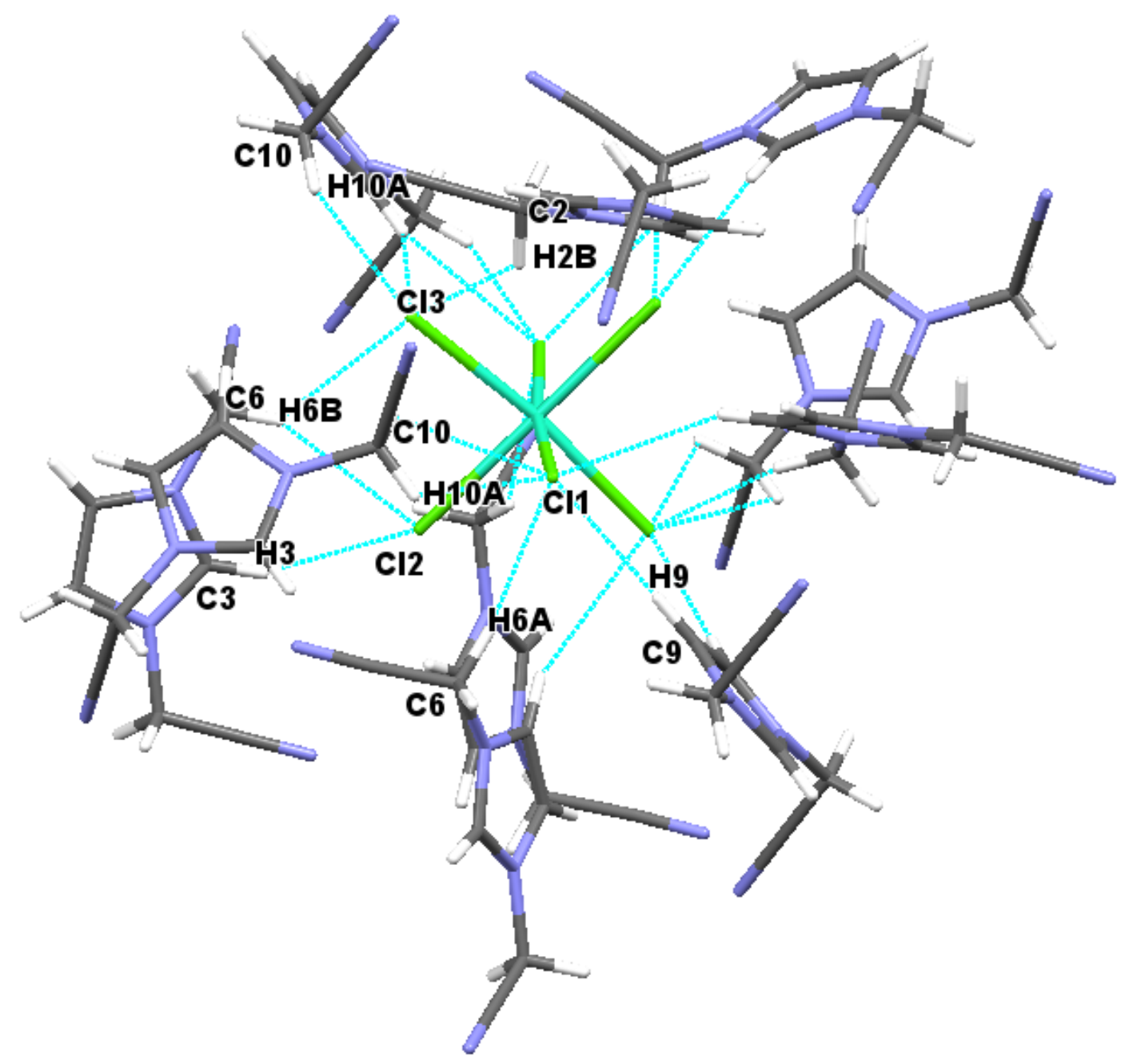

Figure S2. Representation of the different short interactions (dotted cyan line) responsible of the crystal cohesion in $[\mathbf{B i C N I m}]_{3}\left[\mathbf{D y C l}_{6}\right]$.

The study of the short interactions present in the compound $\left[\mathbf{B i C N I m}_{3}\left[\mathbf{D y C l}_{\mathbf{6}}\right]_{\text {reveals }}\right.$ they does not correspond to classical hydrogen bonds (see Table S4). ${ }^{[1,2]}$

Table S4. Characteristic of selected short interactions present in [BiCNIm] $]_{3}\left[\mathrm{DyCl}_{6}\right]$.

\begin{tabular}{ccccc}
\hline Donor--H...Acceptor & D--H $(\AA)$ & H...A $(\AA)$ & D....A $(\AA)$ & D--H...A ( $\left.{ }^{\circ}\right)$ \\
\hline C2--H2B...Cl3 & 0.97 & 2.72 & $3.419(6)$ & 129 \\
C3--H3 ...Cl2 & 0.93 & 2.57 & $3.380(5)$ & 146 \\
C6--H6A...Cl1 & 0.97 & 2.68 & $3.590(5)$ & 157 \\
C6--H6B...Cl3 & 0.97 & 2.73 & $3.478(5)$ & 134 \\
C9--H9...Cl1 & 0.93 & 2.58 & $3.455(6)$ & 158 \\
C10--H10A...Cl3 & 0.97 & 2.58 & $3.473(7)$ & 153 \\
\hline
\end{tabular}




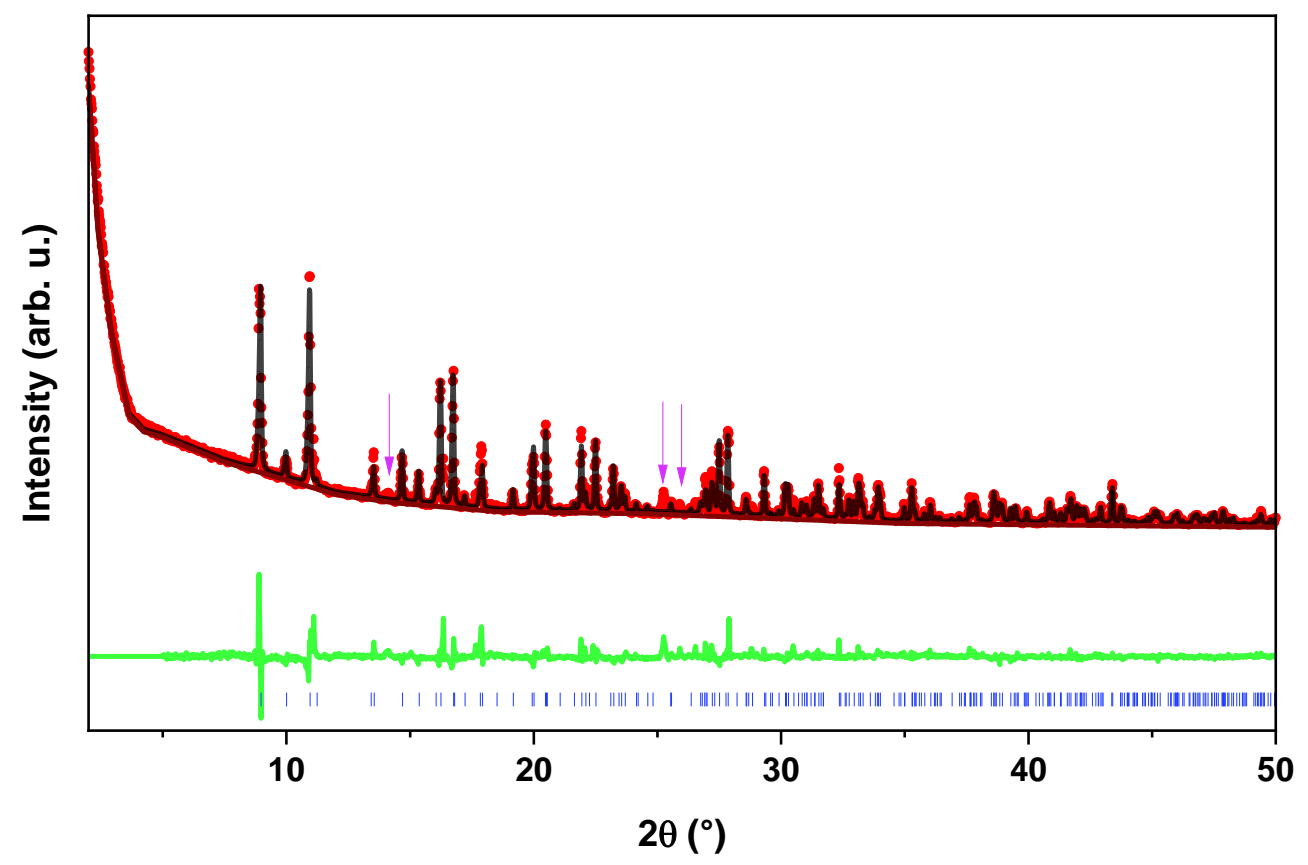

Figure S3. Results of the Rietveld refinement for [BiCNIm] 3 [DyCl6] using the refined parameters $\mathrm{a}=13.12766(25), \mathrm{b}=12.10014(22), \mathrm{c}=19.84414(31), \alpha=90^{\circ}, \beta=90^{\circ}, \gamma=90^{\circ}$ in the orthorhombic space group Pbcn. Red circles correspond to the observed PXRD pattern, black line to the calculated profile, green line to the difference between observed and calculated PXRD and brown line to the background. Vertical blue lines indicate the calculated positions of the diffraction peaks corresponding to these lattice parameters. Purple arrows indicate additional peaks.
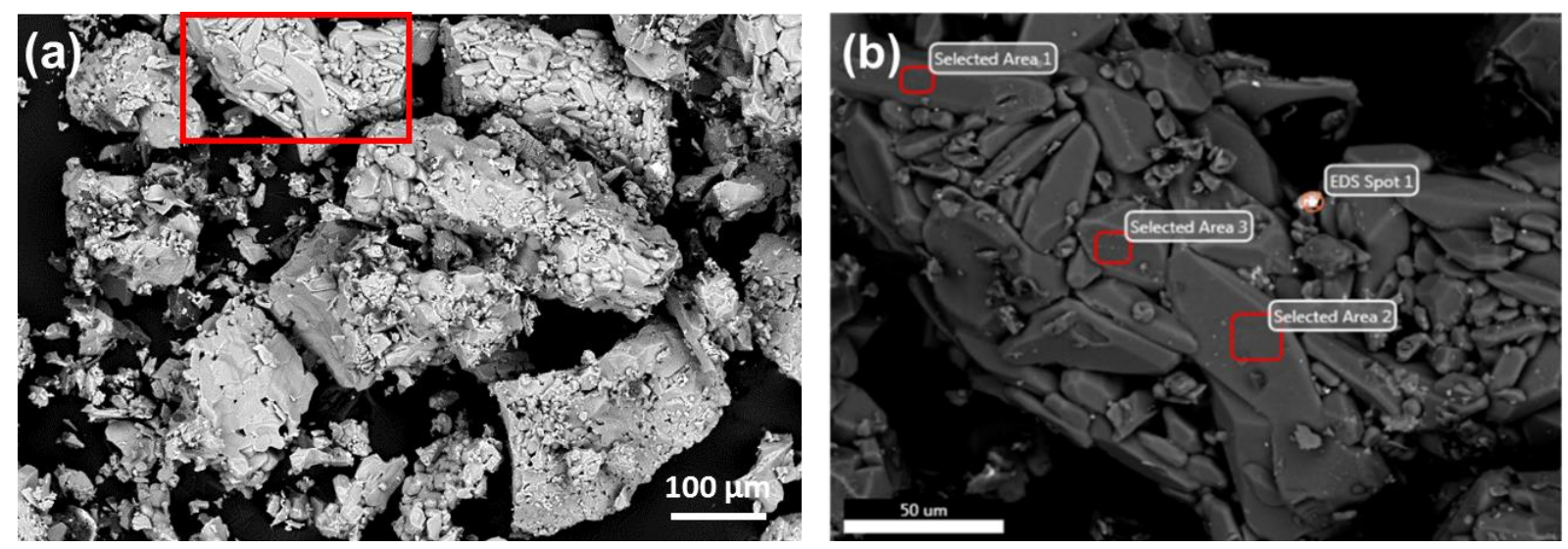

Figure S4. (a) Representative SEM image in composition of the compound [BiCNIm] 3 [DyCl6] and (b) enlargement of the area surrounded in red on which the EDX analyzes have been realized. 
At first glance, the uniformity in the grey scale seems to indicate that the compound [BiCNIm $]_{3}\left[\mathbf{D y C l}_{6}\right]$ is homogeneous (figure S3a) and contains as expected Dy and $\mathrm{Cl}$ (data no shown). However, a closer look has revealed in rare areas that the ratio $\mathrm{Dy} / \mathrm{Cl}$ differs from the expected value (see EDS spot 1 on figure S3b). Indeed, in this case, the area exhibits a ratio of 1 for 1.5 and a high rate in oxygen. This difference is in agreement with the partial hydrolysis of the compound $[\mathrm{BiCNIm}]_{3}\left[\mathrm{DyCl}_{6}\right]$.

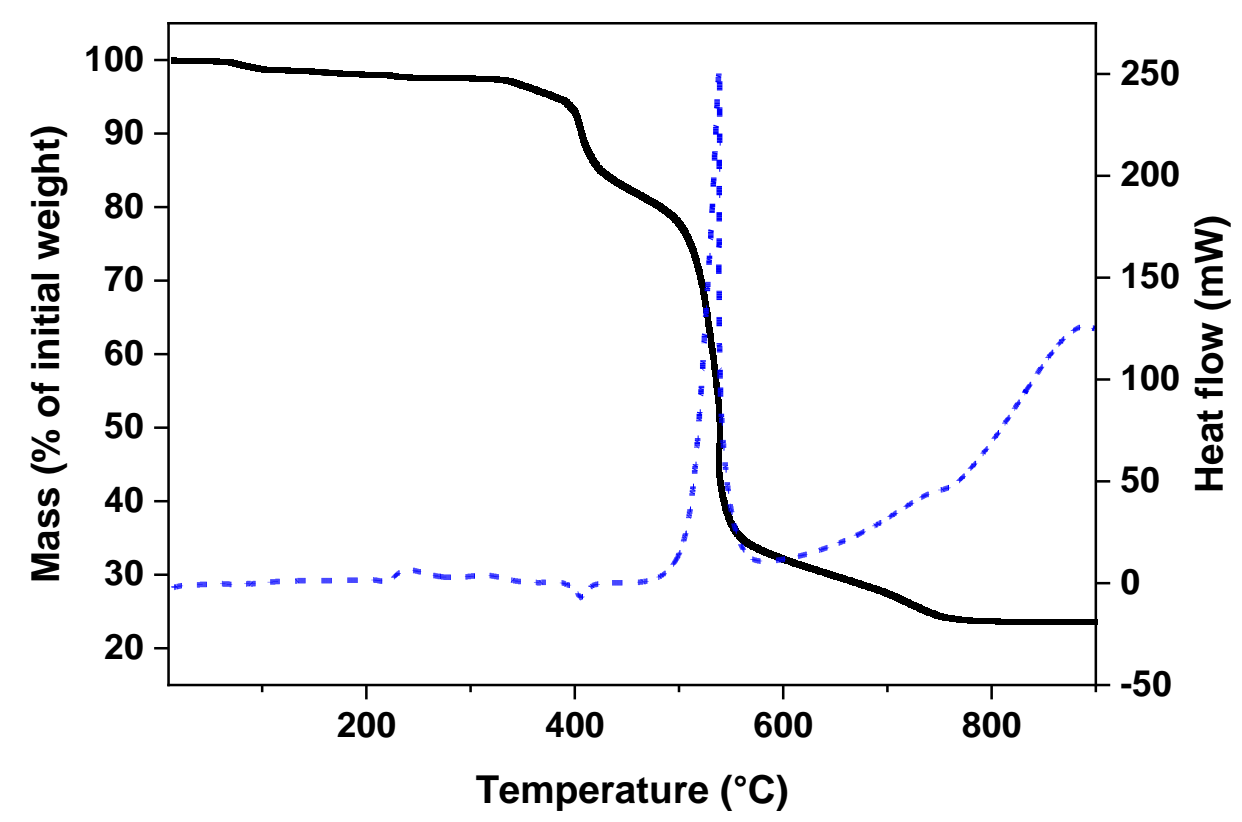

Figure S5. TGA (black line) and TDA (blue dotted line) of the compound [BiCNIm] 3 [DyCl6].

The compound [BiCNIm] $]_{3}\left[\mathbf{D y}_{\mathbf{C}} \mathbf{C l}_{6}\right]$ shows a multistep decomposition and at $900^{\circ} \mathrm{C}$, it has been observed the formation of the oxide $\mathrm{Dy}_{2} \mathrm{O}_{3}$ as identified by PXRD. The experimental total weight loss (experimental: $76.36 \%$ ) is in relatively good agreement with the one calculated (calculated: $75.03 \%$ ) from the formulae of the compound [BiCNIm] $]_{3}\left[\mathrm{DyCl}_{6}\right]$ (Figure S4). 


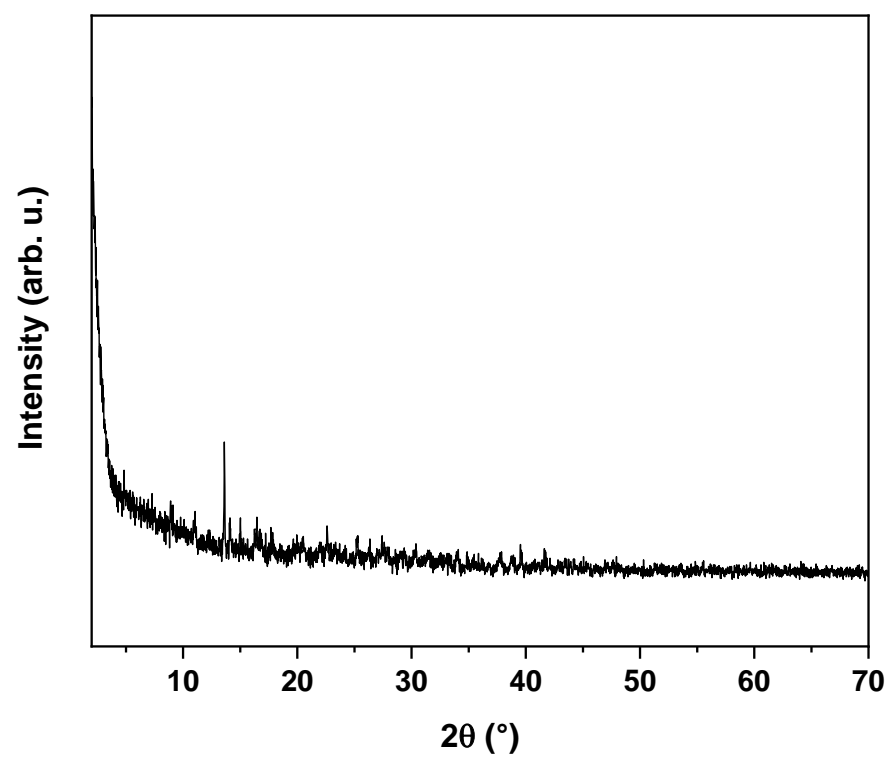

Figure S6. Powder XRD pattern of the compound $[\mathbf{B i C N I m}]_{3}\left[\mathbf{D y C l}_{6}\right]$ after its storage under air after few days.

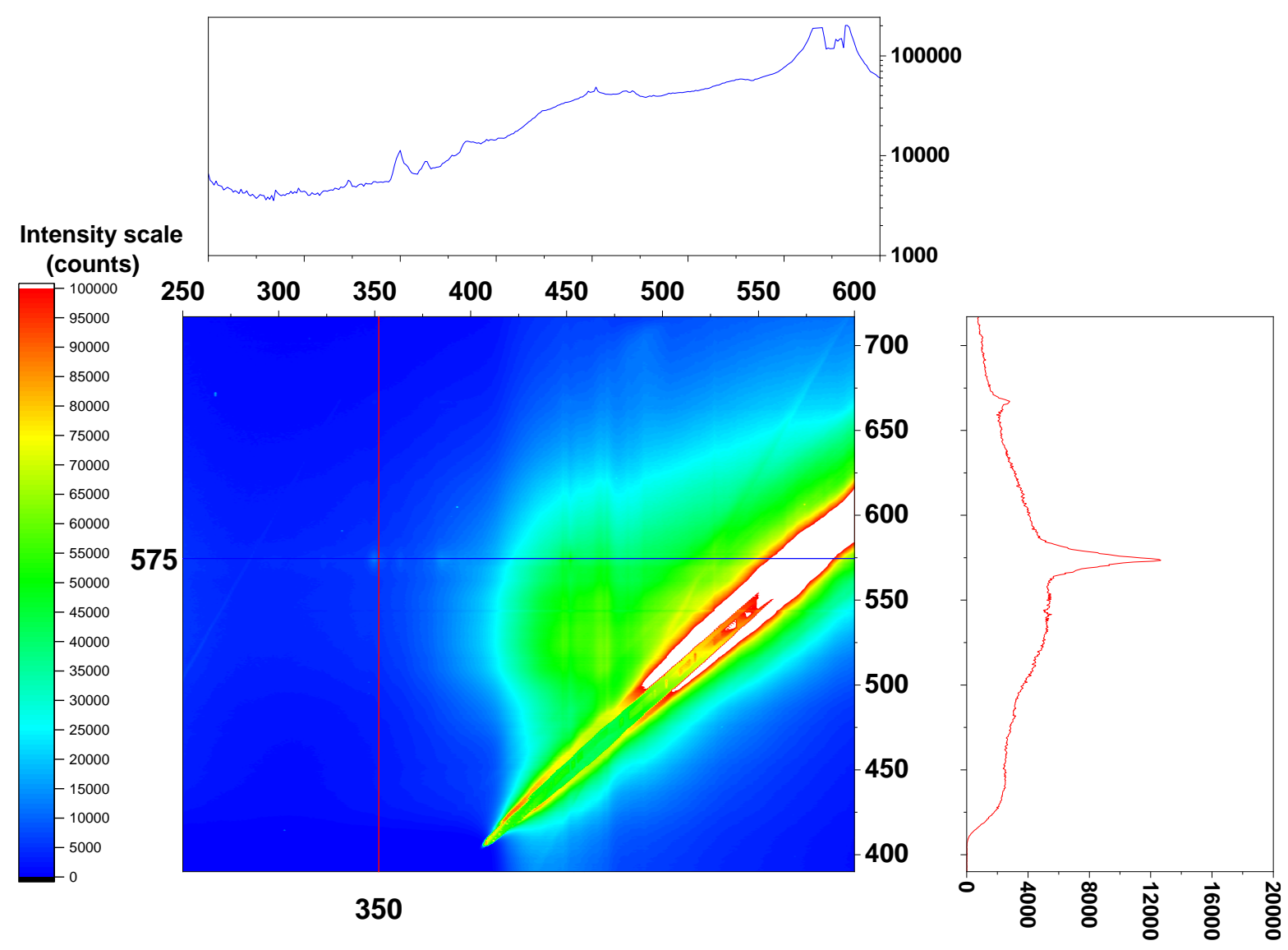

Figure S7. 2D map showing the photoluminescence intensity of the compound $[\mathbf{B i C N I m}]_{3}\left[\mathbf{D y C l}_{6}\right]$ detected in the $350-750 \mathrm{~nm}$ range (vertical axis) as a function of the excitation wavelength (horizontal axis). White area corresponds to saturated intensity. 


\section{Intensity scale}

(counts)

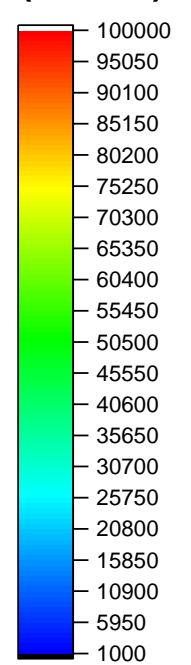

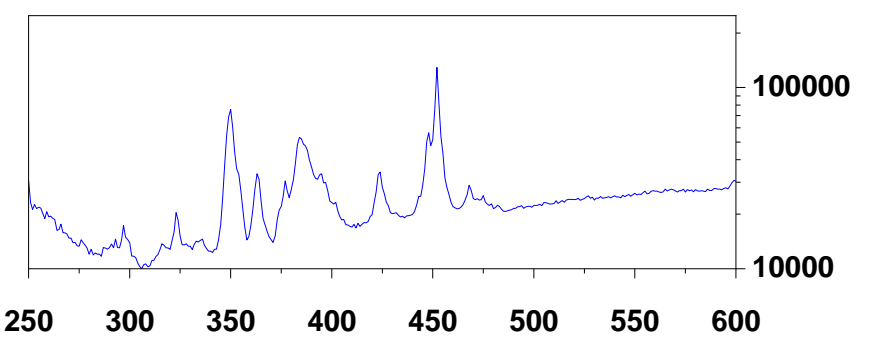

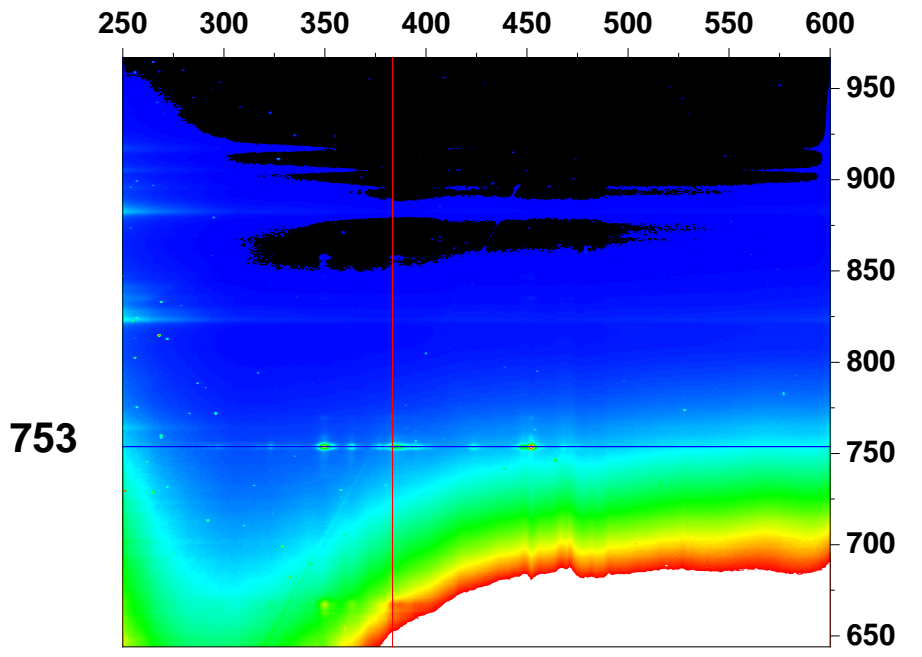

383

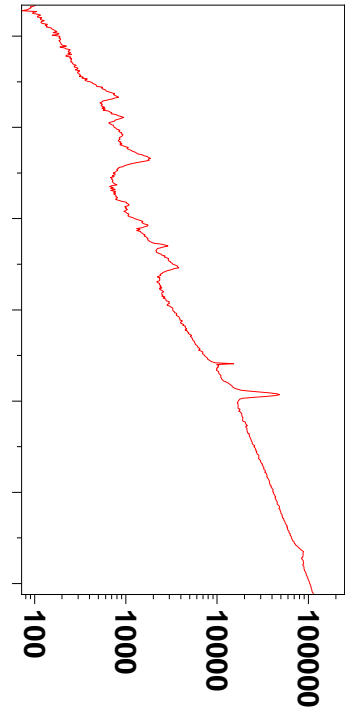

Figure S8. 2D map showing the photoluminescence intensity of the compound $[\mathrm{BiCNIm}]_{3}\left[\mathbf{D y C l}_{6}\right]$ detected in the $600-1000 \mathrm{~nm}$ range (vertical axis) as a function of the excitation wavelength (horizontal axis). White area corresponds to saturated intensity.

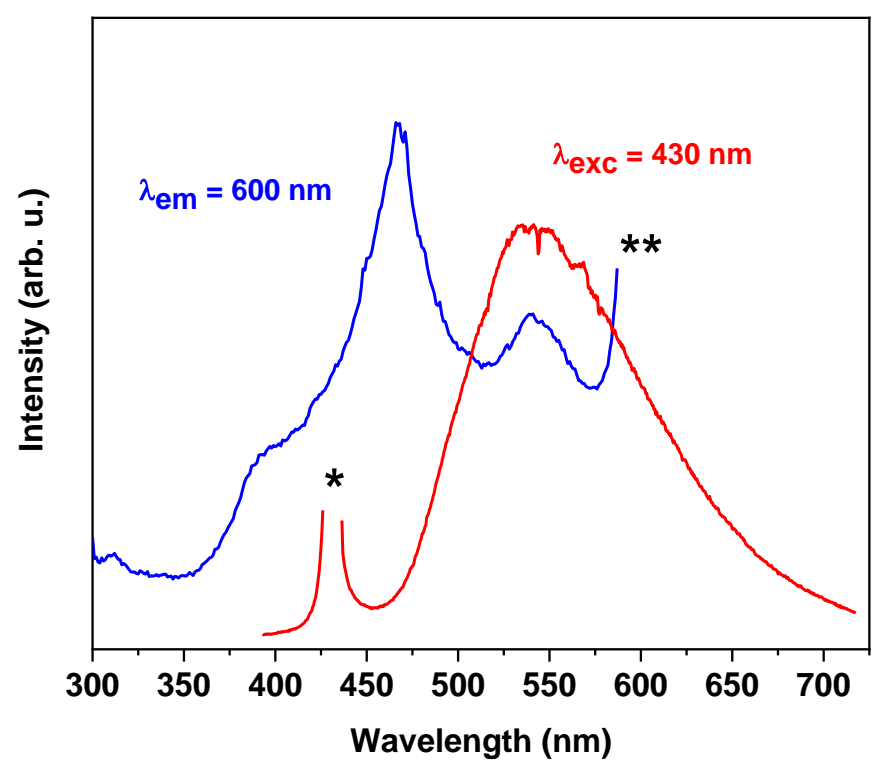

Figure S9. Photoluminescence spectrum (red line), excited at $430 \mathrm{~nm}$, and photoluminescence excitation spectrum (blue line), detected at $600 \mathrm{~nm}$, at room temperature and in solid state for $[\mathbf{B i C N I m}][\mathbf{C l}]$ * Signal coming from $\lambda_{\text {exc }}$ and $* *$ signal coming from $\lambda_{\text {em }}$. 


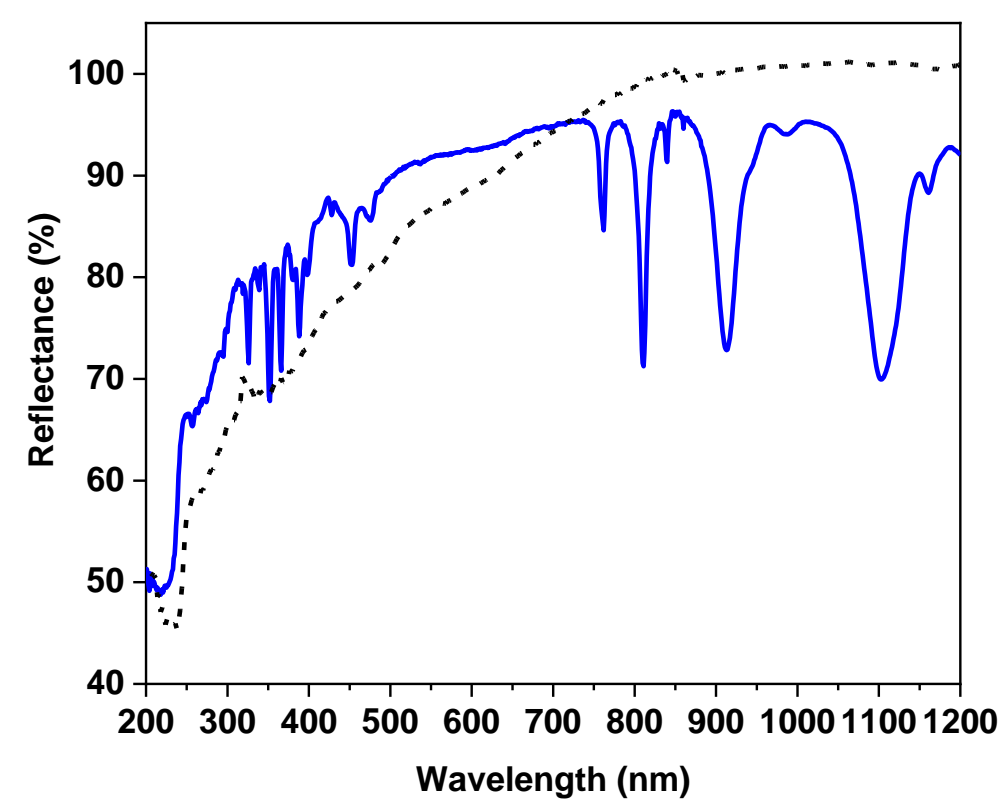

\begin{tabular}{|c|c|}
\hline $\begin{array}{c}\text { Wavelength } \\
(\mathbf{n m})\end{array}$ & Attribution \\
\hline 327 & ${ }^{6} \mathrm{H}_{15 / 2} \rightarrow{ }^{4} \mathrm{~K}_{15 / 2}$ \\
\hline 351 & ${ }^{6} \mathrm{H}_{15 / 2} \rightarrow{ }^{4} \mathrm{M}_{15 / 2}+{ }^{6} \mathrm{P}_{7 / 2}$ \\
\hline 365 & ${ }^{6} \mathrm{H}_{15 / 2} \rightarrow{ }^{4} \mathrm{I}_{11 / 2}$ \\
\hline 388 & $\begin{array}{r}{ }^{6} \mathrm{H}_{15 / 2} \rightarrow{ }^{4} \mathrm{M}_{21 / 2}+{ }^{4} \mathrm{I}_{13 / 2}+ \\
{ }^{4} \mathrm{~K}_{17 / 2}+{ }^{4} \mathrm{~F}_{7 / 2}\end{array}$ \\
\hline 452 & ${ }^{6} \mathrm{H}_{15 / 2} \rightarrow{ }^{4} \mathrm{I}_{15 / 2}$ \\
\hline 475 & ${ }^{6} \mathrm{H}_{15 / 2} \rightarrow{ }^{4} \mathrm{~F}_{9 / 2}$ \\
\hline 759 & ${ }^{6} \mathrm{H}_{15 / 2} \rightarrow{ }^{6} \mathrm{~F}_{3 / 2}$ \\
\hline 811 & ${ }^{6} \mathrm{H}_{15 / 2} \rightarrow{ }^{6} \mathrm{~F}_{5 / 2}$ \\
\hline 911 & ${ }^{6} \mathrm{H}_{15 / 2} \rightarrow{ }^{6} \mathrm{~F}_{7 / 2}$ \\
\hline 1102 & ${ }^{6} \mathrm{H}_{15 / 2} \rightarrow{ }^{6} \mathrm{~F}_{9 / 2}+{ }^{6} \mathrm{H}_{7 / 2}$ \\
\hline
\end{tabular}

Figure S10. UV-Visible-NIR spectra of [BiImCN][CI] (dotted line) and of the compound [BiCNIm] $3\left[\mathbf{D y C l}_{6}\right]$ (blue line) and attribution of the observed transitions.

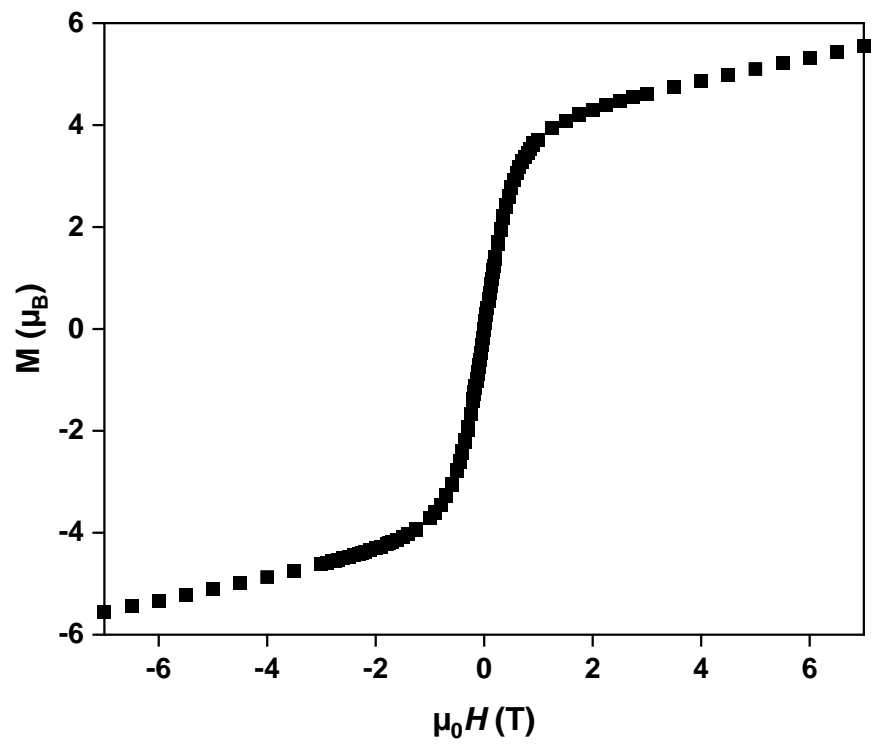

Figure S11. Field-dependence of the magnetization for $\left[\mathrm{BiCNIm}_{3}\left[\mathrm{DyCl}_{6}\right]\right.$ at $1.8 \mathrm{~K}$. 
(a)

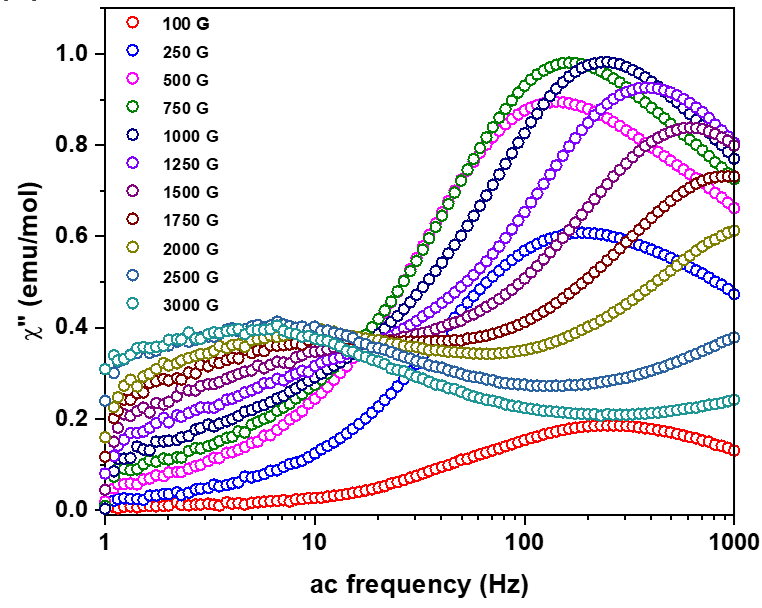

(b)



Figure S12. (a) Out-of-phase susceptibility curves for [BiCNIm $]_{3}\left[\mathrm{DyCl}_{6}\right]$ at $1.8 \mathrm{~K}$ with an ac field of 2 Oe and under various applied dc fields and (b) frequency of the maximum of $\chi$ " as a function of the applied dc field at $1.8 \mathrm{~K}$.

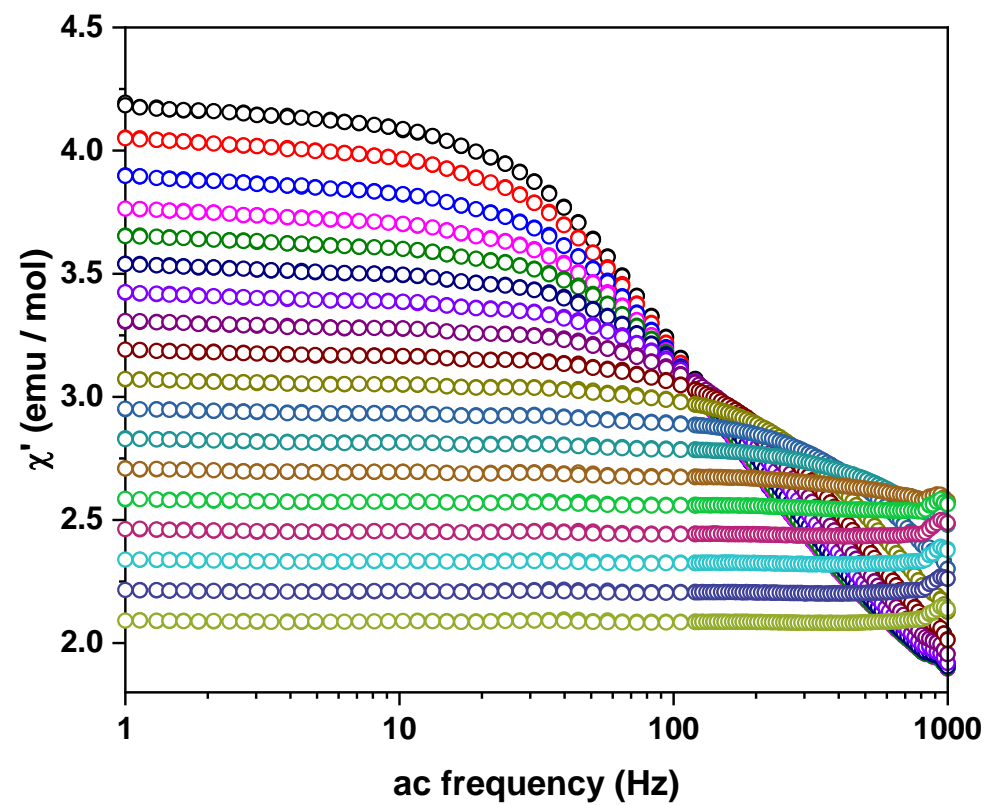

Figure S13. In-phase susceptibility curves for $[\mathbf{B i C N I m}]_{3}\left[\mathbf{D y C l}_{6}\right]$ measured with an $a c$ field of $10 \mathrm{Oe}$ for $10 \mathrm{~Hz}<v<120 \mathrm{~Hz}$ and $2 \mathrm{Oe}$ for $120 \mathrm{~Hz}<v<1000 \mathrm{~Hz}$ under a static $d c$ field of 500 Oe at various temperatures. 


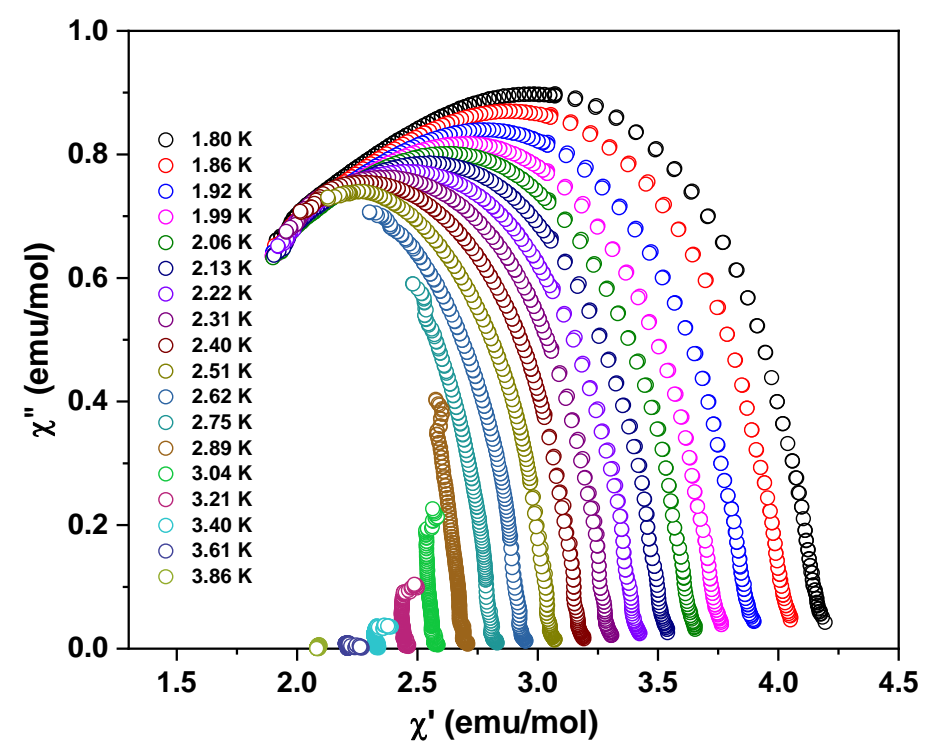

Figure S14. Cole-Cole plot for [BiCNIm] 3 [DyCl6] under a 500 Oe static de field with an ac field of 10 Oe for $10 \mathrm{~Hz}<v<120 \mathrm{~Hz}$ and 2 Oe for $120 \mathrm{~Hz}<v<1000 \mathrm{~Hz}$.

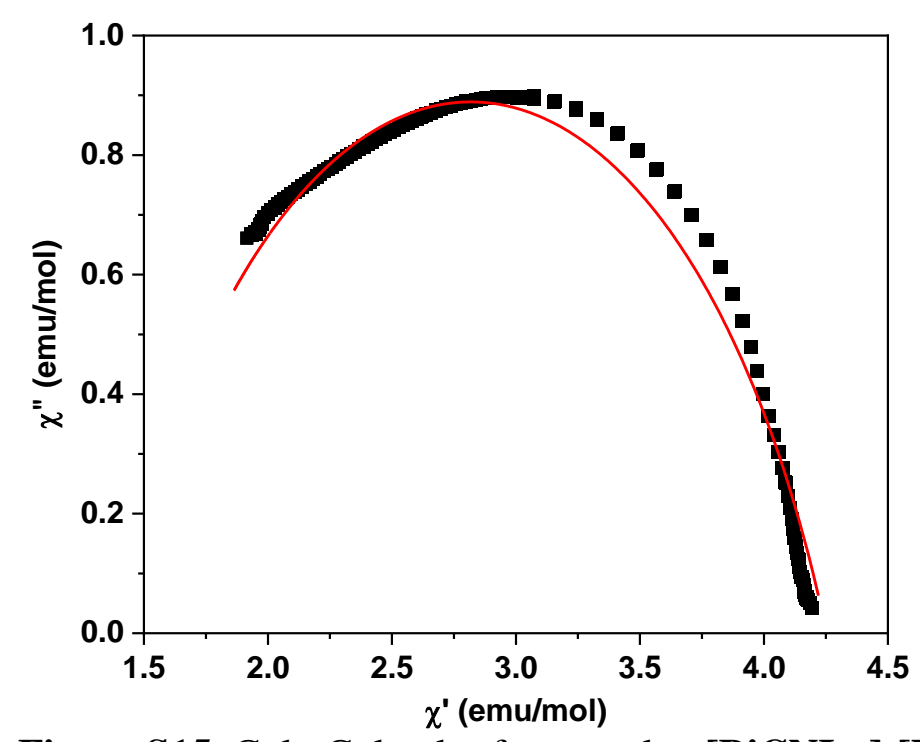

Figure S15. Cole-Cole plot for complex [BiCNIm] $]_{3}\left[\mathbf{D y C l}_{6}\right]$ at $1.8 \mathrm{~K}$ under a 500 Oe static dc field and with an ac field of 10 Oe for $10 \mathrm{~Hz}<v<120 \mathrm{~Hz}$ and 2 Oe for $120 \mathrm{~Hz}<v<1000 \mathrm{~Hz}$. Full red line is the best fit considering a generalized Debye model. 
Table S5. $\tau$ values for each temperature comprised between $1.80 \mathrm{~K}$ and $2.51 \mathrm{~K}$.

\begin{tabular}{|c|c|}
\hline $\mathbf{T}(\mathbf{K})$ & $\boldsymbol{\tau}(\mathbf{m s})$ \\
\hline 1.80 & 1.17 \\
\hline 1.86 & 1.04 \\
\hline 1.92 & 0.890 \\
\hline 1.99 & 0.789 \\
\hline 2.06 & 0.687 \\
\hline 2.13 & 0.569 \\
\hline 2.22 & 0.463 \\
\hline 2.31 & 0.364 \\
\hline 2.40 & 0.260 \\
\hline 2.51 & 0.203 \\
\hline
\end{tabular}

Table S6. Selected bond distances and angles for mononuclear compounds containing Dy ${ }^{3+}$ ions in octahedral environment.

\begin{tabular}{|c|c|c|c|c|c|c|c|}
\hline \multicolumn{4}{|c|}{$\left[\mathrm{DyI}_{3}(\mathrm{Cy} 3 \mathrm{PO})_{2}\left(\mathrm{CH}_{3} \mathrm{CN}\right)\right](\operatorname{ref} 41)$} & \multicolumn{4}{|c|}{$\left[\mathrm{Dy}_{3}\left(\mathrm{Cy}_{3} \mathrm{PO}\right)_{3}\right] \cdot 2 \mathrm{THF}(\operatorname{ref} 41)$} \\
\hline \multicolumn{2}{|c|}{ Bond distances $(\AA)$} & \multicolumn{2}{|c|}{ Angles $\left(^{\circ}\right)$} & \multicolumn{2}{|c|}{ Bond distances $(\AA)$} & \multicolumn{2}{|c|}{ Angles $\left(^{\circ}\right)$} \\
\hline Dy1-I1 & $3.0121(3)$ & I3-Dy1-I2 & $95.594(7)$ & Dy1-I1 & $3.0548(5)$ & I3-Dy1-I2 & $91.664(15)$ \\
\hline Dy1-I2 & $2.9886(3)$ & I2-Dy1-I1 & $95.923(8)$ & Dy1-I2 & $3.0938(5)$ & I3-Dy1-O2 & $84.93(11)$ \\
\hline Dy1-I3 & $3.0595(3)$ & I1-Dy1-N1 & $85.04(4)$ & Dy1-I3 & $3.0973(6)$ & O2-Dy1-I1 & $87.51(11)$ \\
\hline Dy1-N1 & $2.5018(18)$ & N1-I & $83.57(4)$ & Dy & $2.223(4)$ & I1-Dy1-I2 & $96.070(14)$ \\
\hline Dy1-01 & $2.1844(14)$ & O1-Dy & $170.21(5)$ & Dy & $2.213(4)$ & O3-Dy & $170.51(15)$ \\
\hline Dy1-02 & $2.1760(14)$ & I1-D & $92.24(4)$ & Dy1-03 & $2.214(4)$ & I3-D & 90.1 \\
\hline \multicolumn{4}{|c|}{$\left[\mathrm{DyBr}_{3}(\mathrm{OPPh})_{2}(\mathrm{THF})\right] \cdot \mathrm{THF}$ (ref 39) } & \multicolumn{4}{|c|}{$\left[\mathrm{DyCl}_{3}\left(\mathrm{OPPh}_{3}\right)_{2}(\mathrm{THF})\right] \cdot \mathrm{THF}(\operatorname{ref} 39)$} \\
\hline \multicolumn{2}{|c|}{ Bond distances $(\AA)$} & \multicolumn{2}{|c|}{ Angles $\left(^{\circ}\right)$} & \multicolumn{2}{|c|}{ Bond distances $(\AA)$} & \multicolumn{2}{|c|}{ Angles $\left(^{\circ}\right)$} \\
\hline Dy1-Br1 & $2.7843(3)$ & Br2-Dy1-Br1 & $94.029(8)$ & Dy1-Cl1 & $2.6350(5)$ & Cl2-Dy & $95.453(17)$ \\
\hline Dy1-Br2 & $2.7622(3)$ & Br1-Dy1-03 & $85.35(4)$ & Dy1-Cl2 & $2.5909(5)$ & Cl1-Dy1-03 & $86.74(4)$ \\
\hline Dy1-Br3 & $2.7761(3)$ & O3-Dy1-Br3 & $86.03(4)$ & Dy1-Cl3 & $2.6190(5)$ & O3-Dy1-Cl3 & $84.23(4)$ \\
\hline Dy1-03 & $2.3713(15)$ & Br3-Dy1-Br2 & $94.667(8)$ & Dy1-03 & $2.3962(15)$ & Cl3-Dy1-Cl2 & $93.594(17)$ \\
\hline Dy1-02 & $2.2237(15)$ & O1-Dy1-02 & $172.53(6)$ & Dy1-01 & $2.2090(15)$ & O1-Dy1-02 & $170.36(6)$ \\
\hline Dy1-01 & $2.2045(15)$ & Br1-Dy1-01 & $90.98(4)$ & Dy1-02 & $2.2374(15)$ & Cl1-Dy1-01 & $88.05(4)$ \\
\hline
\end{tabular}


Table S6. (Continued).

\begin{tabular}{|c|c|c|c|c|c|c|c|}
\hline \multicolumn{4}{|c|}{$\left[\mathrm{DyCl}_{3}\left(\mathrm{OPPh}_{3}\right)_{3}\right]_{0} .0 .5\left(\left(\mathrm{CH}_{3}\right)_{2} \mathrm{CO}\right)($ ref 37) } & \multicolumn{4}{|c|}{$\left[\mathrm{DyCl}_{2}(\mathrm{ImDippN})(\mathrm{THF})_{3}\right]$ (ref 38) } \\
\hline \multicolumn{2}{|c|}{ Bond distances $(\AA)$} & \multicolumn{2}{|c|}{ Angles $\left(^{\circ}\right)$} & \multicolumn{2}{|c|}{ Bond distances $(\AA)$} & \multicolumn{2}{|c|}{ Angles $\left(^{\circ}\right)$} \\
\hline Dy1-Cl1 & $2.6328(10)$ & Cl2-Dy1-Cl1 & $91.26(3)$ & Dy1-Cl2 & $2.6275(8)$ & O1-Dy1-Cl2 & $85.31(5)$ \\
\hline Dy1-Cl2 & $2.6139(7)$ & Cl1-Dy1-O2 & $86.74(5)$ & Dy1-Cl3 & $2.6307(9)$ & Cl2-Dy1-07 & $87.97(5)$ \\
\hline Dy1-Cl3 & $2.6342(10)$ & O2-Dy1-Cl3 & $89.24(5)$ & -01 & $2.3706(19)$ & O7-Dy1-Cl3 & $92.37(6)$ \\
\hline Dy1-02 & $2.2876(18)$ & Cl3-Dy & $92.97(3)$ & $\mathbf{0 7}$ & $2.3568(19)$ & $\mathbf{C l}$ & $86.72(5)$ \\
\hline Dy1-01 & 2.22 & O1-Dy 1 & $176.95(7)$ & $\mathbf{0 2}$ & $2.508(2)$ & O2-Dy1- & $177.44(7)$ \\
\hline Dy1- & 2.23 & Cl1. & 90.6 & V4 & $2.121(2)$ & $\mathbf{C l}$ & $99.93(7)$ \\
\hline \multicolumn{4}{|c|}{$\left[\mathrm{DyCl}_{2}(\mathrm{OAr})(\mathrm{THF})_{3}\right]($ ref 38) } & \multicolumn{4}{|c|}{$\left[\mathrm{DyR}_{2}(\mathrm{THF})_{4}\right]\left[\mathrm{BPh}_{4}\right]($ ref 42) } \\
\hline \multicolumn{2}{|c|}{ Bond distances $(\AA)$} & \multicolumn{2}{|c|}{ Angles $\left(^{\circ}\right)$} & \multicolumn{2}{|c|}{ Bond distances $(\AA)$} & \multicolumn{2}{|c|}{ Angles $\left(^{\circ}\right)$} \\
\hline Dy1-Cl2 & $2.6122(12)$ & O5-Dy1-Cl2 & $88.35(8)$ & $\mathbf{D y}$ & $2.318(3)$ & O2-Dy1-C & $90.41(12)$ \\
\hline Dy1-06 & $2.353(3)$ & Cl2-1 & $89.35(8)$ & $\mathbf{D}$ & $2.330(4)$ & 01 & $92.06(11)$ \\
\hline Dy1-Cl3 & $2.6303(12)$ & O6-1 & $87.50(8)$ & $\mathbf{D}$ & $4(3)$ & $\mathbf{O}^{3}$ & $88.25(10)$ \\
\hline Dy1-05 & $2.374(3)$ & $\mathrm{Cl3}$ & $91.90(8)$ & & $2.343(3)$ & $\mathbf{O}$ & $89.29(11)$ \\
\hline Dy1-04 & 2.08 & 04-1 & $176.53(18)$ & $\mathbf{D}$ & (4) & $\mathbf{N}$ & $172.31(14)$ \\
\hline Dy & $2.457(8)$ & $\mathbf{C l} 2$ & $97.93(7)$ & & $2.318(4)$ & & 86.3 \\
\hline \multicolumn{4}{|c|}{$\left[\mathrm{DyR}_{2}(\mathrm{py})_{4}\right]\left[\mathrm{BPh}_{4}\right] .2 \mathrm{py}(\operatorname{ref} 42)$} & \multicolumn{4}{|c|}{$\left[\mathrm{Dy}\left(\mathrm{TpMe}_{2}\right)_{2}\right] \mathrm{I}(\operatorname{ref} 35)$} \\
\hline \multicolumn{2}{|c|}{ Bond distances $(\AA)$} & \multicolumn{2}{|c|}{ Angles $\left(^{\circ}\right)$} & \multicolumn{2}{|c|}{ Bond distances $(\AA)$} & \multicolumn{2}{|c|}{ Angles $\left(^{\circ}\right)$} \\
\hline Dy1-N2 & $2.335(3)$ & N4-Dy1-N4a & $88.22(11)$ & Dy1-N3 & $2.376(2)$ & N3-Dy1-N3b & $102.27(12)$ \\
\hline Dy1-N1 & $2.333(3)$ & N4a-Dy1-N3 & $90.56(8)$ & Dy1-N3b & $2.376(2)$ & N3b-Dy1-N3c & $77.73(12)$ \\
\hline Dy1-N4 & $2.485(2)$ & N3-Dy1-N3a & $90.65(12)$ & Dy1-N3c & $2.376(2)$ & N3c-Dy1-N3d & $102.27(12)$ \\
\hline Dy1-N4a & $2.486(2)$ & N3a-Dy1-N4 & $90.56(8)$ & Dy1-N3d & $2.376(2)$ & N3d-Dy1-N3 & $77.73(12)$ \\
\hline Dy1-N3 & $2.470(2)$ & N2-Dy & $178.64(11)$ & -N1 & $2.430(3)$ & N1-D & 180.0 \\
\hline Dy1-N3a & $2.470(2)$ & N2-Dy1-N4 & $89.39(8)$ & Dy1-N1e & $2.430(3)$ & N1-Dy1-N3 & $99.56(8)$ \\
\hline \multicolumn{4}{|c|}{$\left[\mathrm{DyCl}_{2}\left(\mathrm{H}_{3} \mathrm{NAP}\right)_{2}\right] \mathrm{Cl} \cdot \mathrm{EtOH}(\operatorname{ref} 40)$} & \multicolumn{4}{|c|}{$\left[\mathrm{DyCl}_{2}\left(\mathrm{Ph}_{3} \mathrm{AsO}\right)_{4}\right] \mathrm{Cl} \cdot \mathrm{Solv}(\operatorname{ref} 43)$} \\
\hline \multicolumn{2}{|c|}{ Bond distances $(\AA)$} & \multicolumn{2}{|c|}{ Angles $\left(^{\circ}\right)$} & \multicolumn{2}{|c|}{ Bond distances $(\AA)$} & \multicolumn{2}{|c|}{ Angles $\left(^{\circ}\right)$} \\
\hline Dy1-01 & $2.224(3)$ & O1-Dy1-03 & $95.50(15)$ & Dy1-01 & $2.2215(17)$ & 04-Dy1-03 & $86.97(7)$ \\
\hline Dy1-03 & $2.237(4)$ & O3-Dy1-01f & $84.50(15)$ & Dy1-04 & $2.1911(18)$ & O3-Dy1-02 & $92.53(7)$ \\
\hline Dy1-O1f & $2.224(3)$ & O1f-Dy1-O3g & $95.50(15)$ & Dy1-03 & $2.2235(17)$ & O2-Dy1-01 & $88.77(7)$ \\
\hline Dy1-03g & $2.237(4)$ & O3g-Dy1-01 & $84.50(15)$ & Dy1-02 & $2.2012(18)$ & 01-Dy1-04 & $91.72(7)$ \\
\hline Dy1-Cl1 & $2.6656(17)$ & Cl1-Dy1-Cl1f & 180.0 & Dy1-Cl2 & $2.6452(6)$ & Cl1-Dy1-Cl2 & $176.76(2)$ \\
\hline Dy1-Cl1 f & $2.6656(17)$ & Cl1-Dy1-03 & $95.49(10)$ & Dy1-Cl1 & $2.6793(7)$ & O4-Dy1-Cl2 & $91.67(5)$ \\
\hline
\end{tabular}


Table S6. (Continued).

\begin{tabular}{|c|c|c|c|c|c|c|c|}
\hline \multicolumn{4}{|c|}{$\left[\mathrm{DyCl}_{2}\left(\mathrm{OPPh}_{3}\right)_{4}\right] \mathrm{Cl}$. solv (ref 37) } & \multicolumn{4}{|c|}{$\left[\mathrm{DyI}_{2}\left(\mathrm{OPPh}_{3}\right)_{4}\right] \mathrm{I} \cdot \mathbf{4 T H F} \cdot \mathbf{0 . 3 \mathrm { H } _ { 2 } \mathrm { O } ( \text { ref 39) }}$} \\
\hline \multicolumn{2}{|c|}{ Bond distances $(\AA)$} & \multicolumn{2}{|c|}{ Angles $\left(^{\circ}\right)$} & \multicolumn{2}{|c|}{ Bond distances $(\AA)$} & \multicolumn{2}{|c|}{ Angles $\left(^{\circ}\right)$} \\
\hline Dy2-07 & $2.251(4)$ & O7-Dy2-06 & $93.02(16)$ & Dy1-I2 & $3.0386(3)$ & 09-Dy1-OA & $88.47(8)$ \\
\hline Dy2-06 & $2.245(4)$ & O6-D2-04 & $90.89(16)$ & Dy1-I3 & $3.0261(3)$ & OA-Dy1-OB & $92.43(8)$ \\
\hline Dy2-04 & $2.231(4)$ & 04-Dy2-05 & $89.45(15)$ & Dy1-09 & $2.234(2)$ & OB-Dy1-OC & $90.32(8)$ \\
\hline Dy2-05 & $2.254(4)$ & O5-Dy & $86.58(15)$ & Dy1-OA & $2.234(2)$ & OC-Dy1-09 & $89.53(8)$ \\
\hline Dy2-Cl14 & $2.6221(15)$ & Cl14-Dy2-Cl7 & $178.84(5)$ & Dy1-OB & $2.207(2)$ & I3-Dy1-I2 & $176.393(8)$ \\
\hline Dy2-Cl7 & $2.6194(15)$ & Cl14-D & $90.09(11)$ & $\overline{\text { Dy }}$ & $2.220(2)$ & O9-Dy1-I3 & $87.80(6)$ \\
\hline \multicolumn{4}{|c|}{$\left(\mathrm{NMe}_{4}\right)\left[\mathrm{DyCl}_{3}\left(\mathrm{TpMe}_{2}\right)\right]($ ref 35$)$} & \multicolumn{4}{|c|}{$\left[\mathrm{Dy}(\mathrm{L} 2)_{2}\right]($ ref 36) } \\
\hline \multicolumn{2}{|c|}{ Bond distances (§) } & \multicolumn{2}{|c|}{ Angles $\left(^{\circ}\right)$} & \multicolumn{2}{|c|}{ Bond distances (§) } & \multicolumn{2}{|c|}{ Angles $\left(^{\circ}\right)$} \\
\hline Dy1-Cl2 & $2.5979(11)$ & Cl2-Dy1-N5 & $90.52(7)$ & Dy1-01 & $2.207(3)$ & O1-Dy1-N3 & $102.52(11)$ \\
\hline Dy1-N5 & $2.440(2)$ & N5-Dy1-N3 & $73.45(8)$ & Dy1-02 & $2.181(3)$ & N3-Dy1-N4 & $68.88(11)$ \\
\hline Dy1-N3 & $2.422(3)$ & N3-Dy1-Cl3 & $88.00(7)$ & Dy1-N3 & $2.515(3)$ & N4-Dy1-O2 & $99.55(12)$ \\
\hline Dy1-Cl3 & $2.5740(12)$ & Cl3-Dy1-Cl2 & $105.48(5)$ & Dy1-N4 & $2.661(3)$ & O2-Dy1-01 & $89.10(11)$ \\
\hline Dy1-N1 & $2.429(2)$ & Cl1-Dy1-N1 & $175.11(6)$ & Dy1-03 & $2.275(3)$ & O3-Dy1-04 & $155.19(10)$ \\
\hline Dy1-Cl1 & $2.5916(10)$ & Cl2-Dy1-N1 & $87.53(6)$ & Dy1-04 & $2.171(3)$ & 01-Dy1-04 & $93.14(10)$ \\
\hline
\end{tabular}

Symmetry code: (a) x, 1/2-y, z ; (b) 1-x, y, 1-z ; (c) 1-x, 1-y, 1-z ; (d) x, 1-y, z and (e) x, y, z ;

(f) 1-x, 1-y, 1-z and (g) x, y, z. 
Table S7. Crystal field parameters, strength parameters and ab initio energies of the low-lying states for the symmetrized $\left[\mathrm{DyCl}_{6}\right]^{3-}$ complex. Magnetic moments $\mathrm{M}$ are isotropic, $\mathrm{M}_{\mathrm{L}}$ and $\mathrm{M}_{\mathrm{s}}$ denote the orbit and spin contributions.

\begin{tabular}{|c|c|c|c|c|c|c|c|c|c|c|}
\hline \multicolumn{2}{|c|}{$\begin{array}{c}\text { Crystal Field } \\
\text { Parameters } \\
\left(\mathrm{cm}^{-1}\right)\end{array}$} & \multicolumn{2}{|c|}{$\begin{array}{c}\text { Strength } \\
\text { parameters } \\
\left(\mathrm{cm}^{-1}\right)\end{array}$} & \multicolumn{4}{|c|}{ Ab initio energies $\left(\mathrm{cm}^{-1}\right)$} & \multirow[b]{2}{*}{$\begin{array}{l}\mathbf{M}_{\mathbf{L}} \\
\left(\mu_{\mathrm{B}}\right)\end{array}$} & \multirow[b]{2}{*}{$\begin{array}{l}\text { Ms } \\
\left(\mu_{\mathrm{B}}\right)\end{array}$} & \multirow[b]{2}{*}{$\begin{array}{c}\mathbf{M} \\
\left(\mu_{\mathbf{B}}\right)\end{array}$} \\
\hline$B_{q}^{k}$ & & $\mathbf{S}$ & & Term & $\begin{array}{r}\text { SF- } \\
\text { CASSC }\end{array}$ & Term & $\begin{array}{c}\text { SO- } \\
\text { CASSCF }\end{array}$ & & & \\
\hline$B_{0}^{4}$ & 957 & $S^{[\mathrm{a}]}$ & 250 & ${ }^{6} \mathbf{T}_{1 \mathrm{u}}$ & 0 & $\mathbf{E}_{1 / 2 u}$ & 0 & 1.67 & 0.81 & 3.31 \\
\hline$B_{4}^{4}$ & 572 & $S^{4[b]}$ & 417 & ${ }^{6} \mathbf{T}_{2 u}$ & 190 & $F_{3 / 2 u}$ & 21 & $0.27-2.91$ & $0.15-1.41$ & $0.57-5.74$ \\
\hline$B_{0}^{6}$ & 148 & $S^{6}$ & 115 & ${ }^{6} \mathbf{E}_{\mathbf{u}}$ & 301 & $\mathbf{E}_{5 / 2 \mathbf{u}}$ & 98 & 1.89 & 0.93 & 3.76 \\
\hline \multirow[t]{4}{*}{$B_{4}^{6}$} & 32 & $S_{0}^{[\mathrm{c}]}$ & 321 & ${ }^{6} \mathbf{T}_{1 \mathrm{u}}$ & 355 & $F_{3 / 2 u}$ & 201 & $1.55-2.60$ & $0.78-1.25$ & $3.13-5.12$ \\
\hline & & $S_{4}$ & 290 & ${ }^{6} \mathbf{T}_{1 \mathrm{u}}$ & 7563 & $\mathbf{F}_{3 / 2 \mathbf{u}}$ & 245 & $2.13-2.88$ & 1.04- 1.38 & $4.22-5.66$ \\
\hline & & & & ${ }^{6} \mathbf{T}_{2 u}$ & 7700 & $F_{3 / 2 u}$ & 3545 & $0.00-4.64$ & $0.00-0.85$ & $0.01-3.92$ \\
\hline & & & & ${ }^{6} \mathbf{A}_{2 u}$ & 7798 & & & & & \\
\hline
\end{tabular}


Table S8. Crystal field parameters, strength parameters, ab initio energies (Spin-Free and SpinOrbit) of the low-lying states and corresponding g-tensor calculated from the X-ray structure of $[\mathrm{BiCNIm}]_{3}\left[\mathrm{DyCl}_{6}\right]$.

\begin{tabular}{|c|c|c|c|c|c|c|c|c|c|c|}
\hline \multicolumn{3}{|c|}{$\begin{array}{c}\text { Crystal Field } \\
\text { Parameters }\left(\mathrm{cm}^{-1}\right)\end{array}$} & \multicolumn{3}{|c|}{$\begin{array}{l}\text { Strength Parameters } \\
\qquad\left(\mathbf{c m}^{-1}\right)\end{array}$} & \multicolumn{2}{|c|}{$A b$ initio energies $\left(\mathrm{cm}^{-1}\right)$} & \multicolumn{3}{|c|}{ g factors } \\
\hline$B_{q}^{k}$ & $\operatorname{Ref}_{1}$ & $\operatorname{Ref}_{2}$ & $\mathbf{S}$ & $\operatorname{Ref}_{1}{ }^{[a]}$ & $\operatorname{Ref}_{2}^{[b]}$ & SF-CASSCF & $\begin{array}{c}\text { SO- } \\
\text { CASSCF }\end{array}$ & g1 & $\overline{g_{2}}$ & $g_{3}$ \\
\hline$\overline{B_{0}^{2}}$ & 6 & 57 & $S$ & 249 & 249 & 0 & $\overline{0}$ & 8.63 & 6.17 & 5.02 \\
\hline$B_{1}^{2}$ & 46 & 37 & $S^{2}$ & 35 & 35 & 3 & 18 & 8.80 & 6.16 & 3.28 \\
\hline$B_{2}^{2}$ & 29 & 11 & $S^{4}$ & 415 & 415 & 7 & 25 & 10.39 & 0.83 & 0.60 \\
\hline$B_{0}^{4}$ & 777 & 50 & $S^{6}$ & 114 & 114 & 185 & 99 & 7.69 & 7.51 & 7.20 \\
\hline$B_{1}^{4}$ & 371 & 580 & $S_{0}$ & 260 & 31 & 193 & 191 & 16.79 & 0.31 & 0.25 \\
\hline$B_{2}^{4}$ & 99 & 294 & $S_{1}$ & 180 & 276 & 194 & 203 & 8.05 & 7.84 & 2.42 \\
\hline$B_{3}^{4}$ & 150 & 412 & $S_{2}$ & 54 & 159 & 295 & 240 & 8.72 & 1.33 & 0.70 \\
\hline$B_{4}^{4}$ & 552 & 425 & $S_{3}$ & 88 & 198 & 300 & 257 & 11.19 & 8.77 & 1.18 \\
\hline$B_{0}^{6}$ & 101 & 25 & $S_{4}$ & 272 & 201 & 352 & 3543 & & & \\
\hline$B_{1}^{6}$ & 84 & 75 & $S_{5}$ & 38 & 56 & 354 & & & & \\
\hline$B_{2}^{6}$ & 49 & 197 & $S_{6}$ & 11 & 33 & 377 & & & & \\
\hline$B_{3}^{6}$ & 136 & 106 & & & & 7563 & & & & \\
\hline$B_{4}^{6}$ & 202 & 32 & & & & & & & & \\
\hline$B_{5}^{6}$ & 98 & 142 & & & & & & & & \\
\hline$B_{6}^{6}$ & 28 & 85 & & & & & & & & \\
\hline
\end{tabular}

[a] the ligands are approximatively positioned on the $\mathrm{x}, \mathrm{y}, \mathrm{z}$ axes. [b] is the Principal Axes Frame of the g tensor of the ground Kramers doublet.

Lea et al. ${ }^{[3]}$ predict that for a Dy(III) ion in an octahedron, $W$ is positive and $x$ negative, and the ground state either a doublet $E_{5 / 2}$ or a quartet $G_{3 / 2}$ of the $O_{h}^{*}$ double group, depending on the value of $x$. The irreducible representations are denoted according to Mulliken notations. The SF-CASSCF energies of table S7 follow the scheme for $\mathrm{J}=5$ and the SO-energies the scheme for $\mathrm{J}=15 / 2$ with $W>0$ and $-1<x<-0.5$. In other words, the spin-free term of the free ion ${ }^{6} \mathrm{H}$ splits in ${ }^{6} \mathrm{~T}_{1 \mathrm{u}}+{ }^{6} \mathrm{~T}_{2 \mathrm{u}}+{ }^{6} \mathrm{E}_{\mathrm{u}}+{ }^{6} \mathrm{~T}_{1 \mathrm{u}}$ by the field of the ligands, and the spin-orbit term ${ }^{6} \mathrm{H}_{15 / 2}$ splits in $E_{1 / 2 u}+F_{3 / 2 u}+E_{5 / 2 u}+F_{3 / 2 u}+F_{3 / 2 u}$. In the octahedral complex, the states are isotropic. Doublets are described by a pseudo-spin $\tilde{S}=1 / 2$ and the Zeeman Hamiltonian is written as

$$
\widehat{H}=\mu_{B} \boldsymbol{B} \cdot \mathbf{g} \cdot \tilde{\boldsymbol{S}}=\mu_{B} g \boldsymbol{B} \cdot \tilde{\boldsymbol{S}}
$$


where $\mu_{B}$ is the Bohr magneton, $\boldsymbol{B}$ the external magnetic field and $\mathbf{g}$ the g-tensor with an unique g value. Quartets are described by a pseudo-spin $\tilde{S}=3 / 2$ and the Zeeman Hamiltonian is modelled by the following expression ${ }^{[4]}$ :

$$
\widehat{H}=\mu_{B} g \boldsymbol{B} \cdot \tilde{\boldsymbol{S}}+\mu_{B} G\left(B_{x} \tilde{S}_{x}^{3}+B_{y} \tilde{S}_{y}^{3}+B_{z} \tilde{S}_{z}^{3}\right)
$$

In Table S7, the isotropic magnetic moments are given for each manifold with orbit and spin contributions. For doublets, $g=2 M$, the ground KD has a $\mathrm{g}$ factor of 6.62 with equivalent and additive contributions from spin and orbit. For quartets, the determination of the two $g$ and $G$ factors needs to assign the $\left|\widetilde{M}_{J}\right\rangle$ components to the ab initio states. ${ }^{[5]}$ In Table S7, we give the two values of the magnetic moment and their orbit and spin contributions. In the $1^{\text {st }}$ excited quartet, one of the component has an important magnetic moment of $5.74 \mu_{B}$, with equivalent and additive spin and orbit contributions, the other component is much less magnetic. Crystal field parameters were deduced from the ground $\mathbf{J}$ manifold using the Irreducible Tensors Operators technique and are given in Table S7.

The powder magnetic properties deduced from the symmetrized and X-rays structures are similar. A comparison with experimental values is shown in figures S15 and S16. The calculated plateau for the $\chi T$ curve is at $14.17 \mathrm{emu} . \mathrm{K}_{\mathrm{mol}} \mathrm{mol}^{-1}$ as expected for $\mathrm{Dy}^{3+}$ ion, while the experimental values are about $10 \%$ lower. The decrease at low temperature follows the experimental trend, and is due to the depopulation of the excited states. The low field behaviour of the theoretical magnetization versus field curve is the correct one, which confirms that the nature of the ground KD is correct predicted, but the slope at high field is too large, which is a sign that the gap with the low excited states is too small. One gets the correct behaviour, when the $1^{\text {st }}$ quartet is moved up by $20 \mathrm{~cm}^{-1}$. 


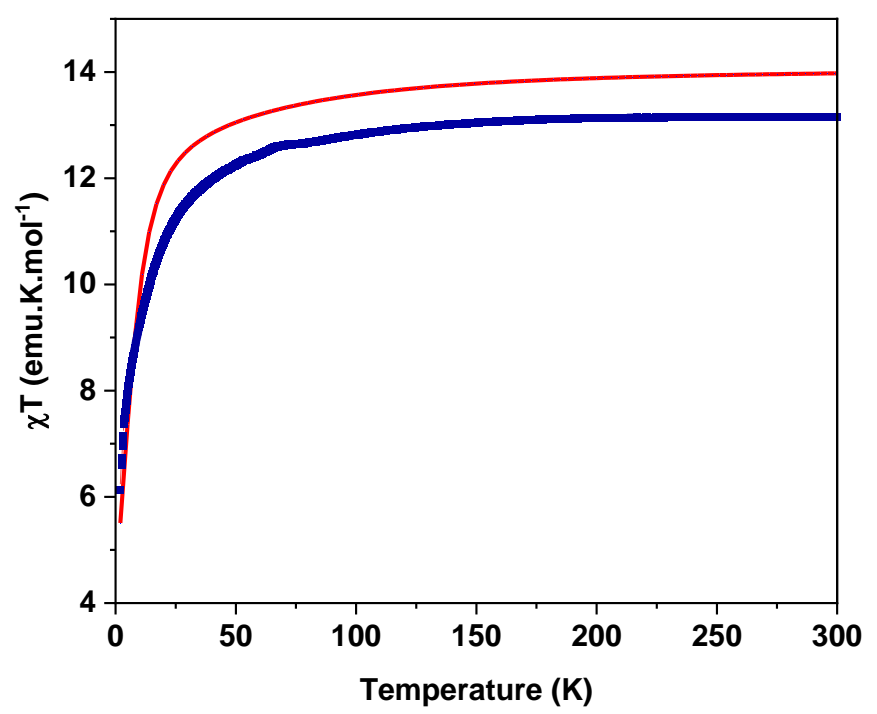

Figure S15. $\chi \mathrm{T}$ vs $\mathrm{T}$ : experimental (blue squares) and calculated from SO-CASSCF for the $\left[\mathrm{DyCl}_{6}\right]^{3-}$ complex with the X-rays geometry (red line).

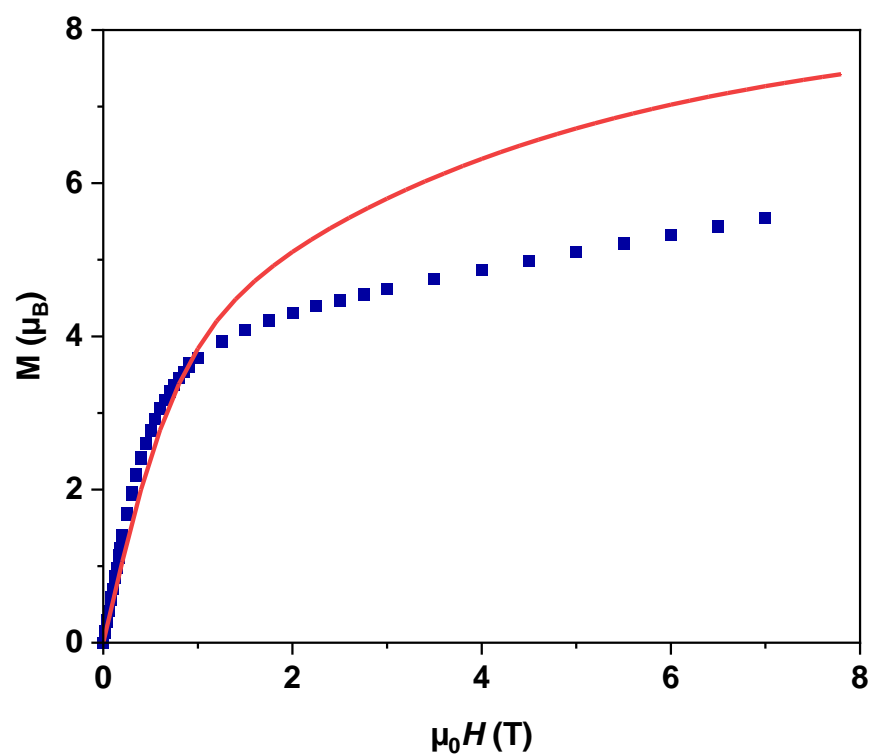

Figure S16. Magnetization $v s$ magnetic field at $1.8 \mathrm{~K}$ : experimental (blue squares) and calculated from SO-CASSCF for the $\left[\mathrm{DyCl}_{6}\right]^{3-}$ complex with the X-rays geometry (red line).

\section{References}

[1] T. Steiner, Angew. Chem. Int. Ed. 2002, 41, 48-76.

[2] G. A. Jeffrey, H. Maluszynska, J. Mitra, Int. J. Biol. Macromol. 1985, 7, 336-348.

[3] K. R. Lea, M. J. M. Leask, W. P. Wolf, J. Phys. Chem. Solids 1962, 23, 1381-1405.

[4] B. Bleaney, Proc. Phys. Soc. 1959, 73, 939-942.

[5] D. P. Hernández, H. Bolvin, J. Electron Spectrosc. Relat. Phenom. 2014, 194, 74-80. 